\author{
Universidade de São Paulo \\ Instituto de Física
}

\title{
Sílica Mesoporosa Ordenada Luminescente
}

Aline dos Santos Lira Durães

Orientadora: Prof ${ }^{\mathrm{a}}$ Dr$^{\mathrm{a}}$ Márcia Carvalho de Abreu Fantini

Dissertação de mestrado apresentada ao Instituto de Física para a obtenção do título de Mestre em Ciências

Comissão examinadora:

Prof ${ }^{\mathrm{a}}$. Dr ${ }^{\mathrm{a}}$. Márcia Carvalho de Abreu Fantini (IF-USP)

Prof. Dr. Giancarlo Espósito de Souza Brito (IF-USP)

Prof $^{\mathrm{a}}$. Dr ${ }^{\mathrm{a}}$. Tereza da Silva Martins (UNIFESP-Diadema)

São Paulo

2014 


\section{FICHA CATALOGRÁFICA}

Preparada pelo Serviço de Biblioteca e Informação do Instituto de Física da Universidade de São Paulo

\begin{tabular}{|l}
\hline 2014 Durães, Aline dos Santos Lira \\
Sílica Mesoporosa Ordenada Luminescente - São Paulo, \\
Dissertação (Mestrado) - Universidade de São Paulo. \\
Instituto de Física - Depto. Física Aplicada. \\
Orientadora: Profa Dra Márcia Carvalho de Abreu Fantini \\
Área de Concentração: Física da Matéria Condensada \\
Unitermos: \\
1. Física da Matéria Condensada; \\
2. Espalhamento de raios X a baixos ângulos; \\
3. Isotermas de absorção de nitrogênio; \\
4. Luminescência; \\
5. Feixes
\end{tabular}




\section{Agradecimentos}

a orientadora Profa. Dra. Márcia C. A. Fantini do Laboratório de Cristalografia do IF-USP pela oportunidade, por ter me ajudado nos primeiros passos no ramo científico e por sua amizade, compreensão e extrema paciência em todos os momentos.

ao Prof. Dr. Osvaldo A. Sant'Anna do Laboratório de Imunologia do Instituto Butantã e coordenador do projeto ao qual faço parte.

ao Prof. Dr. Hermi Felinto Brito do Instituto de Química da USP - São Paulo

ao Prof. Dr. Manfredo Tabacniks do Instituto de Física da USP - São Paulo

ao Prof. Dr. Sidney José Lima Ribeiro do Instituto de Química da UNESP - campus Araraquara

a todos os professores, técnicos, alunos e ex-alunos do Laboratório de Cristalografia do IF-USP com quem convivi desde os tempos de Iniciação Científica.

as Dras. Ana Valéria e Claudia Akemi do IQ-USP pela ajuda, apoio e amizade ao longo do projeto.

a Cristália Indústria Farmacêutica pelo apoio financeiro.

ao CNPq e à FAPESP.

aos amigos que fiz antes de entrar no IF e aos que conheci ao longo do período de graduação e pós-graduação no IF-USP.

aos meus familiares que suportaram meus momentos de crise, principalmente minha mãe e meu pai que, mesmo não estando mais presente, me dão forças para continuar seguindo e lutando pelo o que acredito. 



\section{Sumário}

\begin{tabular}{ll}
\hline Agradecimentos & iii
\end{tabular}

Resumo ix

Abstract xi

1 Estado da arte 1

1.1 Aplicações de materiais mesoporosos ordenados luminescentes . . . . . 1

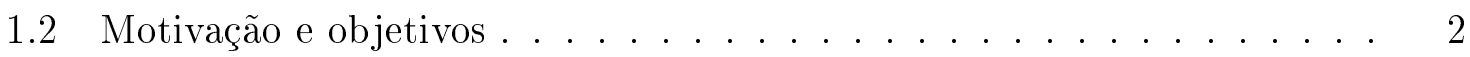

\begin{tabular}{|lll}
2 & Técnicas experimentais & 5
\end{tabular}

2.1 Difração de raios X (XRD) . . . . . . . . . . . . . . . 5

2.2 Espalhamento de raios X a baixo ângulo (SAXS) $\ldots \ldots \ldots \ldots$

2.3 RBS (Rutherford Backscattering Spectroscopy) $\ldots \ldots \ldots \ldots$

2.3 .1 Breve abordagem sobre RBS . . . . . . . . . . . . . . . 9 9

2.3 .2 Interpretação e análise de um espectro de RBS. . . . . . . . . 10

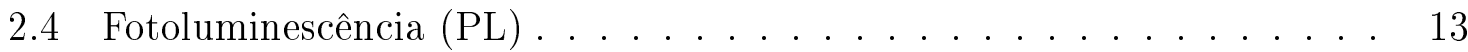

$2.4 .1 \quad$ Espectroscopia eletrônica de terras raras . . . . . . . . . . . 13

2.5 Técnicas Complementares . . . . . . . . . . . . . . 15

2.5.1 Microscopia Eletrônica de Varredura (MEV) . . . . . . . . . . 15

2.5 .2 Isotermas de Adsorção-Dessorção de Nitrogênio (NAI) $\ldots . .16$

$\begin{array}{lll}3 & \text { Amostras preparadas: resultados e discussão } & 19\end{array}$

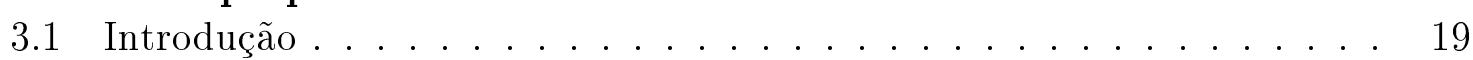

3.2 Sínteses das amostras . . . . . . . . . . . . . . . . . . . 21

3.2 .1 Com e sem repouso após tratamento térmico . . . . . . . . . 21

3.3 Resultados . . . . . . . . . . . . . . . . . . . . . . . . 22

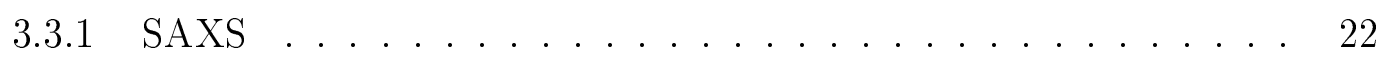

3.3 .2 Luminescência . . . . . . . . . . . . . . . . . . 25

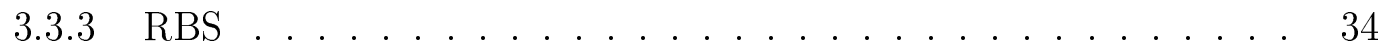

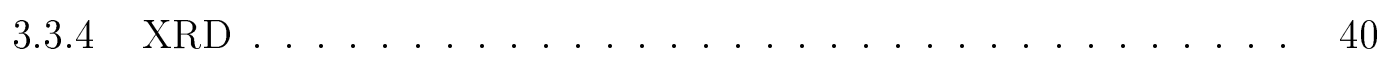




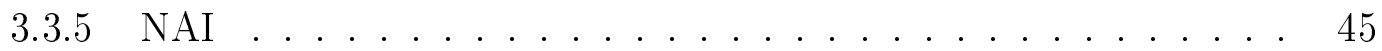

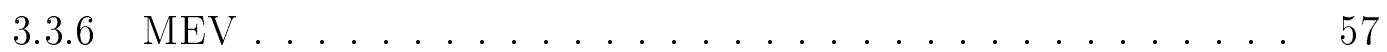

4 Comparação dos resultados e conclusões $\quad 61$

4.1 Comparação dos Resultados e conclusões . . . . . . . . . . . . . . . . . 61

\begin{tabular}{ll}
\hline Referências & 66
\end{tabular} 


\section{Lista de Figuras}

1.1 Estruturas de poros hexagonal, cúbica e lamelar da família M41S (L. C. Cides da Silva, IQ-USP. Dissertação de Mestrado, 2003). . . . . . . . . 2

2.1 Representação da difração de raios X por um cristal. . . . . . . . . . 6

2.2 Montagem para um equipamento de SAXS [6]. . . . . . . . . . . . . 7

2.3 Perfis de intensidade de espalhamento, onde $\mathrm{x}=\mathrm{q}$ (vetor de espalha-

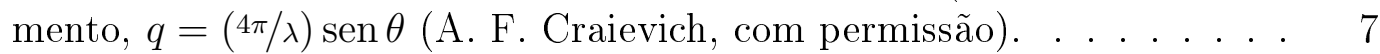

2.4 Perfis de intensidade espalhada em gás, líquido e um sólido organizado, onde $\epsilon=2 \theta$ (A. F. Craievich, com permissão). . . . . . . . . . 8

2.5 Arranjo estrutural de poros hexagonal da sílica SBA-15[7]. . . . . . . . 8

2.6 Diagrama de um arranjo experimental para experimento de RBS. [29] . 10

2.7 Espectro RBS de um filme de $\mathrm{SiO}_{2}$ sobre carbono. [29] $[\ldots \ldots$. . . . . 11

2.8 (a) Representação dos tipos de isotermas de adsorção descritos por Brunauer; (b) Representação dos tipos de histereses em isotermas de

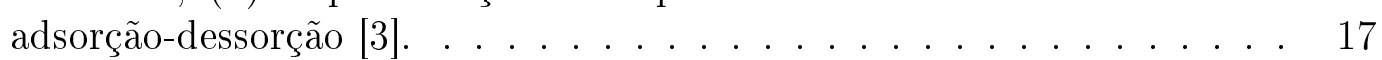

3.1 Diagrama esquemático de síntese de SBA-15 com material luminescente. 20

3.2 Espalhamento de raios X a baixo ângulo das amostras contendo európio. 23

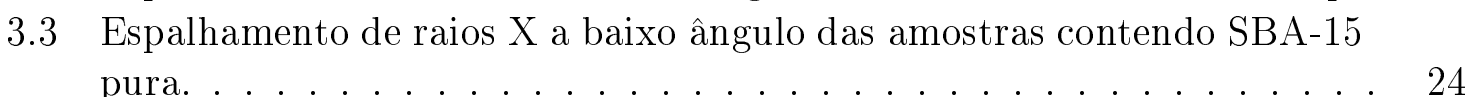

3.4 Espectro de luminescência das amostras A e D. . . . . . . . . . . 26

3.5 Espectro de luminescência das amostras B e C. . . . . . . . . . . . . 27

3.6 Espectro de luminescência das amostras A e B. . . . . . . . . . . . 27

3.7 Espectro de luminescência das amostras C e D. . . . . . . . . . . 28

3.8 Espectro de luminescência das amostras A, B C e D. . . . . . . . . . 29

3.9 Tempo de vida das amostras A, B C e D. . . . . . . . . . . . . . . . . . . . 29

3.10 Espectro de luminescência da amostra A. . . . . . . . . . . . . . . . 32

3.11 Espectro de luminescência da amostra B. . . . . . . . . . . . . . . . . . 32

3.12 Espectro de luminescência das amostras C. . . . . . . . . . . . . . . 32

3.13 Espectro de luminescência das amostras D. . . . . . . . . . . . . . . . . . . . . . . 33

3.14 Simulação do da composição da amostra A. . . . . . . . . . . . 36 
3.15 Simulação do da composição da amostra B. . . . . . . . . . . . . . 37

3.16 Simulação do da composição da amostra C. . . . . . . . . . . . . . . . . 38

3.17 Simulação do da composição da amostra D. . . . . . . . . . . . . . . . . . . . . . 39

3.18 Resultado de XRD da amostra B. . . . . . . . . . . . . . . 41

3.19 Resultado de XRD da amostra C. . . . . . . . . . . . . . . . . . . . 41

3.20 Resultado de XRD da amostra A. . . . . . . . . . . . . . . . . 42

3.21 Resultado de XRD da amostra D. . . . . . . . . . . . . . . . 42

3.22 Resultado de XRD das amostras até $650^{\circ} \mathrm{C}$. . . . . . . . . . 43

3.23 Resultado de XRD das amostras até $900^{\circ} \mathrm{C}$. . . . . . . . . . . . 43

3.24 Isoterma da amostra B (Eu com sobrenadante e sem repouso). . . . . . 46

3.25 Distribuição do tamanho de poros da amostra B (Eu com sobrenadante e sem repouso). . . . .................. 46

3.26 Isoterma da amostra C (Eu com sobrenadante e com repouso). . . . . . 47

3.27 Distribuição do tamanho de poros da amostra C (Eu com sobrenadante e com repouso). ........................ 47

3.28 Isoterma da amostra A (Eu sem sobrenadante e sem repouso). . . . . . 49

3.29 Distribuição do tamanho de poros da amostra A (Eu sem sobrenadante e sem repouso). ........................ 49

3.30 Isoterma da amostra D (Eu sem sobrenadante e com repouso). . . . . . 50

3.31 Distribuição do tamanho de poros da amostra D (Eu sem sobrenadante

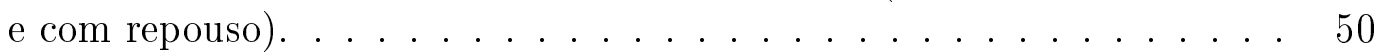

3.32 Isoterma da amostra E (SBA-15 com sobrenadante e sem repouso). . . 53

3.33 Distribuição do tamanho de poros da amostra E (SBA-15 com sobrenadante e sem repouso). . . . . . . . . . . . . . 53

3.34 Isoterma da amostra G (SBA-15 com sobrenadante e com repouso). . . 54

3.35 Distribuição do tamanho de poros da amostra G (SBA-15 com sobrenadante e com repouso). . ................... 54

3.36 Isoterma da amostra F (SBA-15 sem sobrenadante e sem repouso). . . 55

3.37 Distribuição do tamanho de poros da amostra F (SBA-15 sem sobrenadante e sem repouso). . . . . . . . . . . . . 55

3.38 Isoterma da amostra H (SBA-15 sem sobrenadante e com repouso). . . 56

3.39 Distribuição do tamanho de poros da amostra H (SBA-15 sem sobrenadante e com repouso). . . . . . . . . . . . . . 56

3.40 Aspecto morfológico da amostra A. . . . . . . . . . . . . . . . . . 57

3.41 Aspecto morfológico da amostra B. . . . . . . . . . . . . . . . . . . . 57

3.42 Aspecto morfológico da amostra C. . . . . . . . . . . . . . 58

3.43 Aspecto morfológico da amostra D. . . . . . . . . . . . . . . . 58

3.44 Aspecto morfológico da amostra E. . . . . . . . . . . . . . . 59

3.45 Aspecto morfológico da amostra F. . . . . . . . . . . . . . . . . . . . . 59

3.46 Aspecto morfológico da amostra G. . . . . . . . . . . . . . . . . . 60

3.47 Aspecto morfológico da amostra H. . . . . . . . . . . . 60 


\section{Resumo}

O objetivo desse projeto foi o de produzir sílica mesoporosa ordenada (SMO) do tipo SBA-15 com fósforos. A incorporação dos fósforos às paredes da sílica foi realizada através de um único processo de síntese. Os métodos experimentais utilizados para caracterização das amostras foram: RBS (Rutherford Backscattering Spectrometry) para a análise química, SAXS (Small Angle X Ray Scattering), XRD (X Ray Diffraction) e NAI (Nitrogen Adsorption Isotherms) para a análise estrutural destes materiais, além da fotoluminescência. Para a caraterização morfológica complementar das amostras, foi utilizado o SEM (Scanning Electron Microscopy). A incorporação de Eu na matriz de sílica preserva a estrutura de poros ordenada. Os resultados de XRD mostraram a formação de óxidos de európio. A partir dos resultados obtidos observaram-se diferentes efeitos da presença e ausência de sobrenadante durante o período de secagem nas amostras preparadas, como por exemplo, alterações de morfologia. As amostras preparadas com sobrenadante apresentaram menor área superficial e volume de poros. Materiais que mantiveram o sobrenadante apresentaram maior conteúdo de Eu e maior intensidade de luminescência. 



\begin{abstract}
The aim of this project was to synthesize ordered mesoporous silica (OMS) with phosphorus. The incorporation of phosphorus to the silica walls was performed by means of a one pot synthesis process. The experimental methods used to characterize the samples were: RBS (Rutherford Backscattering Spectrometry) for chemical analysis, SAXS (Small Angle X Ray Scattering), XRD (X Ray Diffraction) and NAI (Nitrogen Adsorption Isotherms) for structural analysis, besides fluorescence. SEM (Scanning Electron Microscopy) was used for complementary morphological characterization of the samples. The Eu incorporation in the silica matrix preserves the ordered mesoporous structure. The XRD results showed the presence of europium oxides. The presence and absence of the liquid solution during the drying process caused the formation of samples with different properties, as, for example, modification in morphology. Samples prepared in the presence of the liquid solutions showed smaller surface area and pore volume. Materials prepared with the liquid solution during the drying process presented larger Eu content and higher photoluminescence intensity.
\end{abstract}





\section{Capítulo 1}

\section{Estado da arte}

\subsection{Aplicações de materiais mesoporosos ordenados luminescentes}

A descoberta de materiais mesoporosos ordenados com tamanhos de poros de 10-50 nm (SBA-15, SBA-16, FDU-1) se deu nos anos de 1990. Esses materiais, preparados a partir de moldes de polímeros co-blocos, tornou a síntese mais simples, além de contribuir para a diminuição dos custos de preparação e permitir o uso de material biodegradável [5]. Sílicas mesoporosas ordenadas podem apresentar fases hexagonais, cúbicas e lamelares. Seguem abaixo os seus respectivos padrões de difração de raios X [23][2].

A formação de estruturas hexagonais, cúbicas ou lamelares em sílicas mesoporosas ordenadas depende dos tipos de precursores e das condições de síntese. Como condição de síntese, podem ser consideradas as concentrações de co-polímero, tempo de tratamento da amostra e temperatura de tratamento hidrotérmico.

Atualmente a pesquisa em materiais porosos ordenados tem por objetivo controlar o tamanho, a forma e a uniformidade do espaço "vazio" e os átomos e moléculas que o definem.

Neste trabalho, a sílica mesoporosa utilizada para estudo foi a SBA-15. A SBA15 pode ser utilizada como veículo de antígenos e tem gerado resultados promissores, mostrando a potencialidade desse material para aplicações biológicas.

Além de veículo de antígenos, as sílicas porosas podem ser utilizadas como materiais luminescentes, ou seja, atuando como sondas em sistemas de interesse biológico.

Terras raras foram utilizadas devido às suas amplas aplicações vastamente publicadas na literatura [2] [18]. Por apresentarem bandas finas nos espectros de emissão e excitação, tornam-se excelentes marcadores luminescentes [17] [4] [33] [21]. 


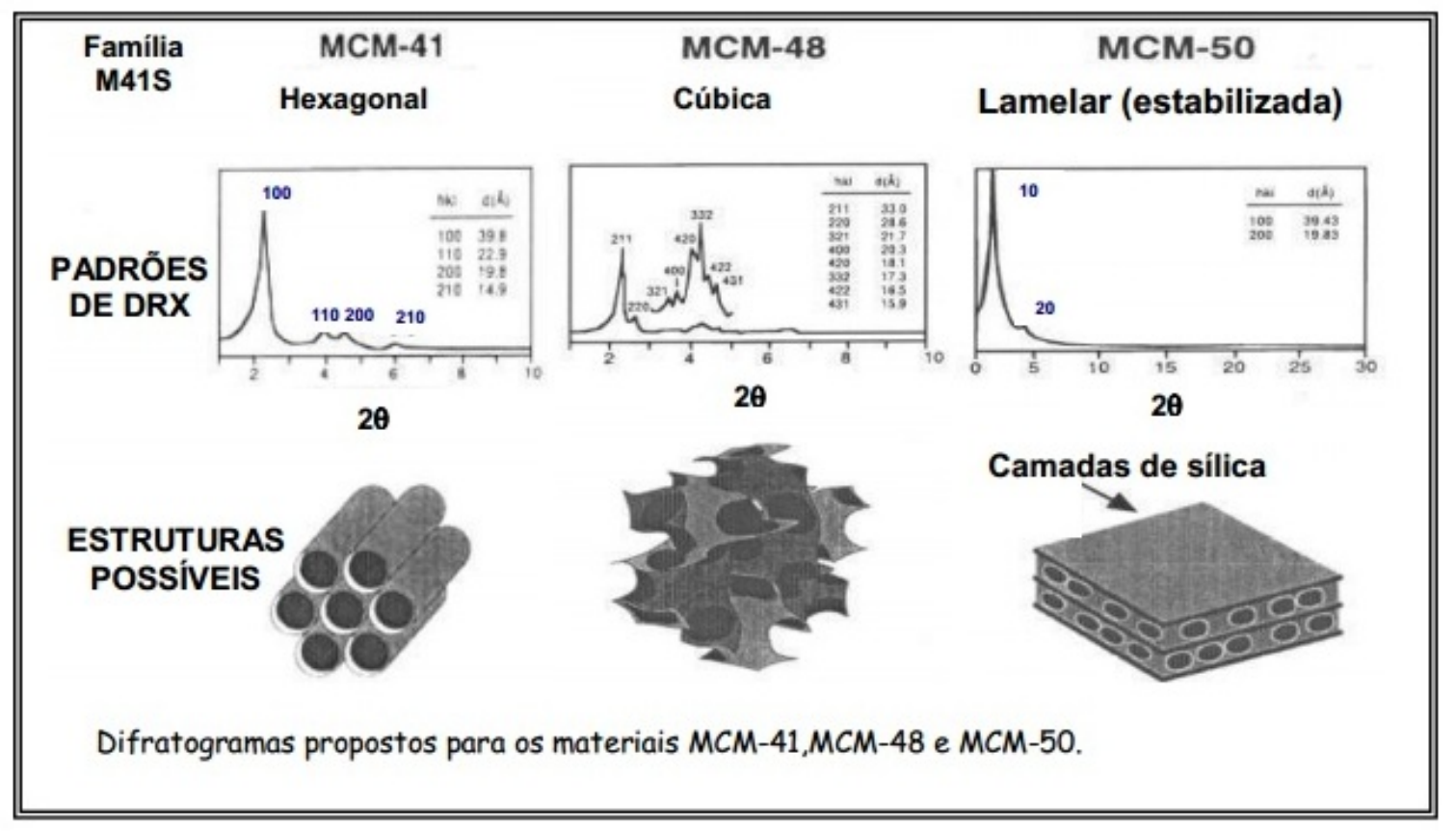

Figura 1.1: Estruturas de poros hexagonal, cúbica e lamelar da família M41S (L. C. Cides da Silva, IQ-USP. Dissertação de Mestrado, 2003).

\subsection{Motivação e objetivos}

O objetivo deste trabalho foi o de produzir silica mesoporosa ordenada luminescente, através de processo one pot synthesis. O processo utilizado não deve alterar as propriedades estruturais do material.

Nesse trabalho, utilizamos o cromóforo európio $(\mathrm{Eu})$ sob a forma de nitrato.

As concentrações nominais molares estudadas foram $\mathrm{x}=3,5$ e $10 \%$. Neste trabalho serão apresentados apenas os resultados referentes ás amostras contendo $\mathrm{x}=10 \%$. Essas concentrações foram escolhidas de tal forma que as propriedades estruturais da sílica SBA-15 pura fossem preservadas [18] [23] [32]. Estudos sistemáticos para $\mathrm{x}=10 \%$ foram realizados neste trabalho, pois esta concentração produz o maior conteúdo de Eu no material final.

As técnicas de análise utilizadas ao longo do projeto foram: Espalhamento de Raios X a Baixo Ângulo (análise da estrutura ordenada dos poros), Difração de Raios X (análise da estrutura das paredes), Isotermas de Adsorção de $\mathrm{N}_{2}$ (avaliar a distribuição de tamanho de poros e área superficial), Fotoluminescência (análise de propriedades luminescentes na região do ultravioleta visível), Termogravimetria (verificar temperatura necessária para a decomposição do polímero), Microscopia Eletrônica de Varredura 
(análise morfológica) e Retroespalhamento Rutherford (análise e simulação da composição elementar) [21] 31] 34].

A seguir, no capítulo 2 serão apresentados os métodos de caracterização utilizados ao longo do projeto. No capítulo 3 serão apresentadas as amostras produzidas ao longo da execução do trabalho e os resultados obtidos serão apresentados e discutidos de forma qualitativa. No capítulo 4 os resultados serão comparados quantitativamente e as conclusões serão apresentadas. 



\section{Capítulo 2}

\section{Técnicas experimentais}

\subsection{Difração de raios X (XRD)}

A difração de raios X é um fenômeno de interação entre a radiação eletromagnética e a matéria ordenada. Para que ocorra da difração de raios X a altos ângulos é necessário que o comprimento de onda da radiação incidente seja da mesma ordem de grandeza do espaçamento interatômico $(\lambda \approx 0,1 \mathrm{~nm})$.

Após incidência dos raios $\mathrm{X}$ sobre um átomo há o espalhamento de radiação em todas as direções. A difração ocorre em decorrência da interferência construtiva dos raios X espalhados [8].

Para os cristais, a sequência periódica de átomos pode ser visualizada como um conjunto de planos cristalográficos. Os planos cristalográficos são indexados através dos índices de Miller (hkl)[8].

Quando a energia da radiação incidente é a mesma para um conjunto de planos cristalográficos e ocorre espalhamento em um ângulo bem definido (ângulo de Bragg), temos o fenômeno de difração. A condição de difração é estabelecida pela lei de Bragg. A figura 2.1, onde os planos XX' e YY' estão separados por uma distância $\mathrm{d}_{h k l}$, mostra um feixe de raios $\mathrm{X}$ incidente, em fase, em um sólido organizado (cristal) e o feixe espalhado pelos elétrons no sólido em $\mathrm{O}$ e O’ [8].

A diferença de caminho ótico entre esses feixes é dada pela distância $\overline{A B C}$ e o ângulo de espalhamento entre o feixe incidente e espalhado é dado por $\widehat{A O C}=2 \theta$. Através da figura, temos que:

$$
\overline{A B}=\overline{B C}=d_{h k l} \operatorname{sen} \theta
$$

A condição de interferênia construtiva (pico) ocorre se a diferença de fase entre os feixes espalhados por O e O' é um múltiplo de $2 \pi$. Para isso a diferença de caminho ótico entre os dois feixes deve ser um múltiplo inteiro do comprimento de onda, logo: 


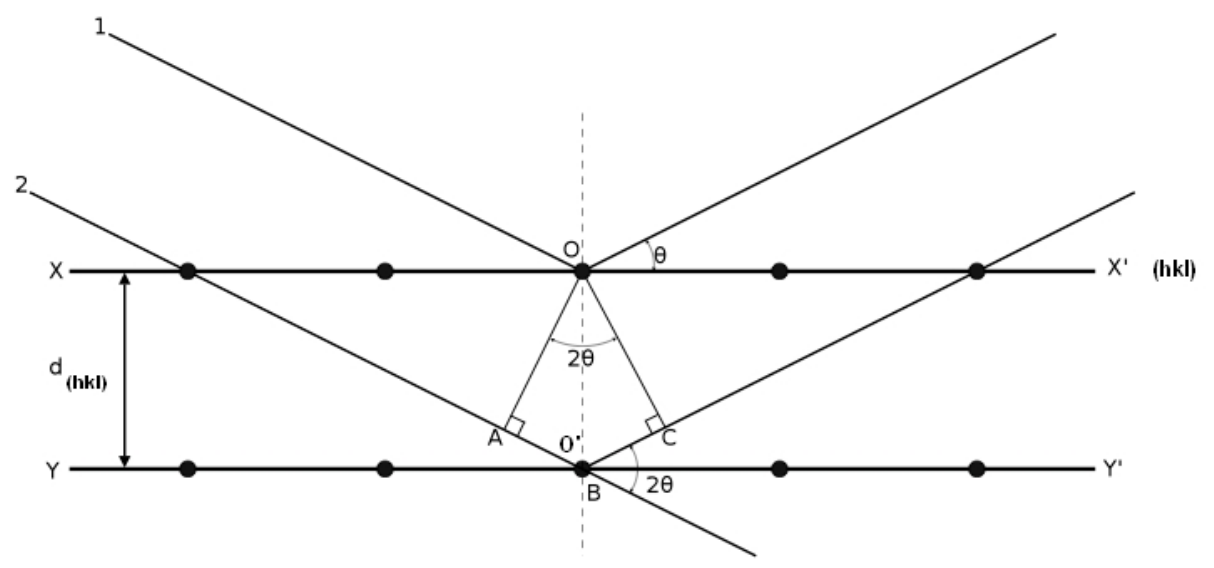

Figura 2.1: Representação da difração de raios X por um cristal.

$$
m \lambda=2 d_{h k l} \operatorname{sen} \theta_{h k l}
$$

onde $\lambda$ é o comprimento de onda da radiação incidente, $\mathrm{d}_{h k l}$ é a distância interplanar e $\theta_{h k l}$ é o semi-ângulo de difração medido em relação aos raios $\mathrm{X}$ incidentes e $\mathrm{m}$, a ordem de difração. A equação 2.2 é a Lei de Bragg para a difração de raios X. Os valores de $\mathrm{d}_{h k l}$ para compostos padrão estão tabelados, disponíveis no sistema ICDD (JCPDS) [8].

Neste trabalho, as amostras contendo európio foram analisadas por XRD no Laboratório de Cristalografia do IF-USP. O equipamento utilizado nesses experimentos foi um difratômetro da marca Rigaku, modelo Ultima Plus.

Para garantir a homogeneidade e a orientação aleatória dos grãos morfológicos das amostras, estas foram trituradas em almofariz de ágata após prévio aquecimento em estufa. Em uma lamínula foi utilizada graxa de vácuo, material que não interfere nas medidas por não apresentar picos de difração, e acima da graxa foi prensado o material para análise. Com auxílio de uma segunda lamínula, o material é prensado e distribuído. O tratamento térmico citado antes do material ser aplicado na lamínula torna-se necessário pois as amostras são higroscópicas.

As condições de medida para as amostras foram de $40 \mathrm{kV}$ e $30 \mathrm{~mA}$, radiação $\mathrm{K}_{\alpha}$ do cobre $(\lambda=0,15418 \mathrm{~nm})$ com o ângulo $2 \theta$ variando de 10 a $90^{\circ}$, com o tempo de contagem de $10 \mathrm{~s}$ a cada passo de $0.05^{\circ}$ e $15 \mathrm{rpm}$ de rotação do porta-amostra.

\subsection{Espalhamento de raios $\mathrm{X}$ a baixo ângulo (SAXS)}

Técnica utilizada para a análise de partículas ou poros em uma matriz de densidade eletrônica homogênea. Dados de SAXS podem ser utilizados para analisar e 
caracterizar materiais com diferentes densidades eletrônicas.

A técnica de espalhamento de raios $\mathrm{X}$ a baixo ângulo está associada a medidas de ângulos de espalhamento em torno de 0,1 a $10^{\circ}$, onde esses limites dependem do arranjo experimental.

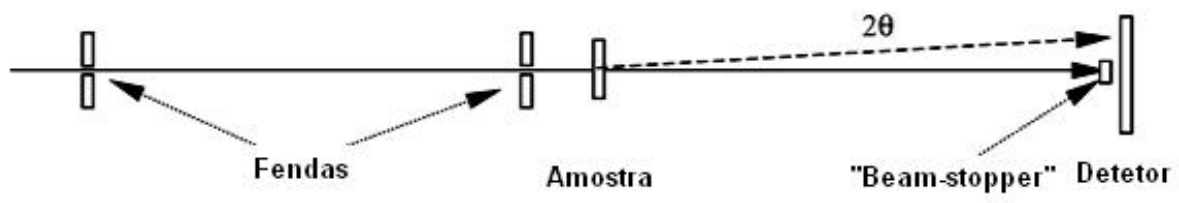

Figura 2.2: Montagem para um equipamento de SAXS [6].

O método de transmissão é um dos mais utilizados em um experimento de SAXS da Figura 2.2. pois, para cada perfil de organização das partículas, será obtido um perfil de espalhamento conforme apresentado nas figuras abaixo 2.3 e 2.4 .
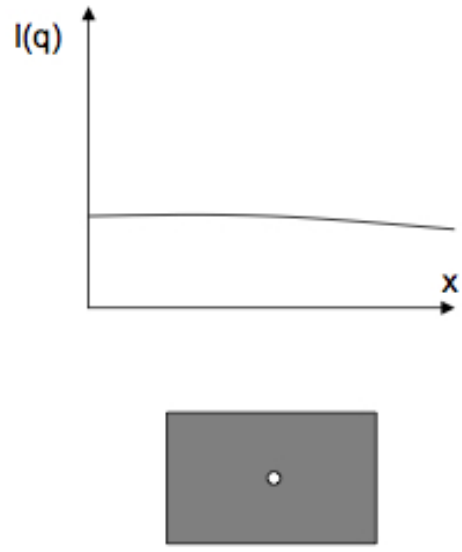

$\mathrm{R} 1 \approx 1 \mu \mathrm{m}$
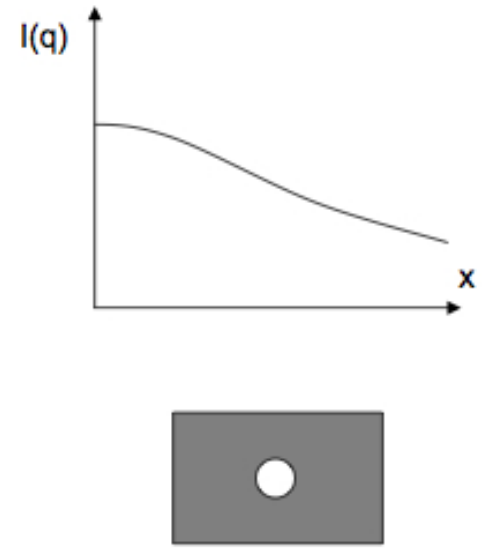

$\mathrm{R} 2 \approx 5 \mu \mathrm{m}$
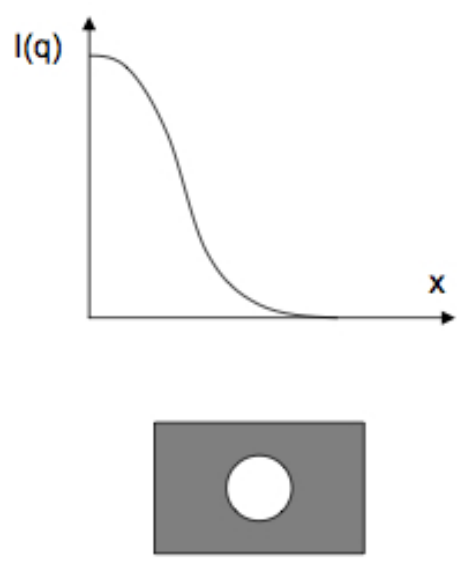

$\mathrm{R} 3 \approx 20 \mu \mathrm{m}$

Figura 2.3: Perfis de intensidade de espalhamento, onde $\mathrm{x}=\mathrm{q}$ (vetor de espalhamento, $q=(4 \pi / \lambda) \operatorname{sen} \theta$ (A. F. Craievich, com permissão). 

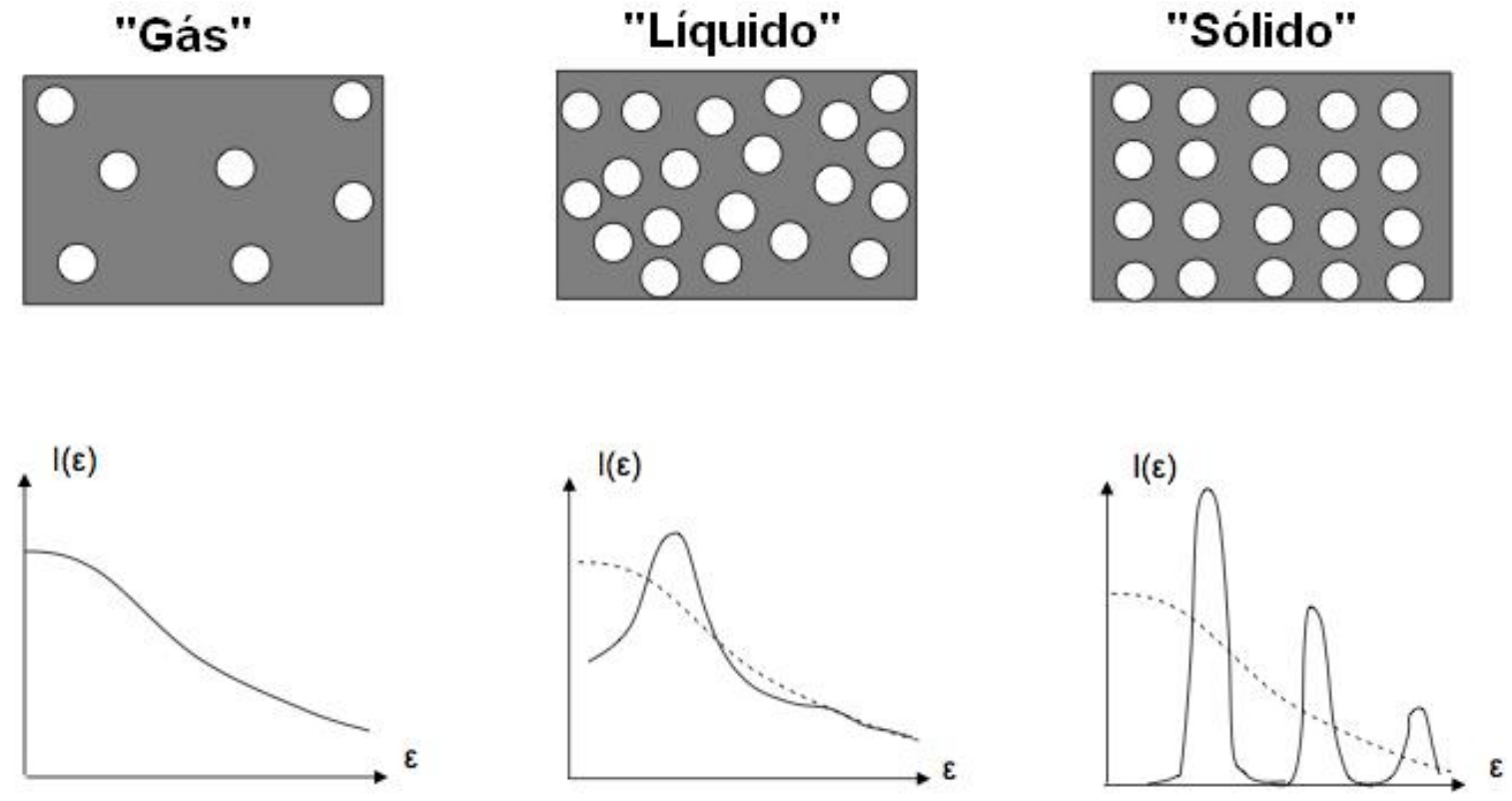

Figura 2.4: Perfis de intensidade espalhada em gás, líquido e um sólido organizado, onde $\epsilon=2 \theta$ (A. F. Craievich, com permissão).

No caso das sílicas mesoporosas, como a SBA-15, que apresenta diâmetro de poro em torno de $2 \lesssim \mathrm{d} \lesssim 50 \mathrm{~nm}$, a estrutura hexagonal se dá conforme a figura 2.5 .

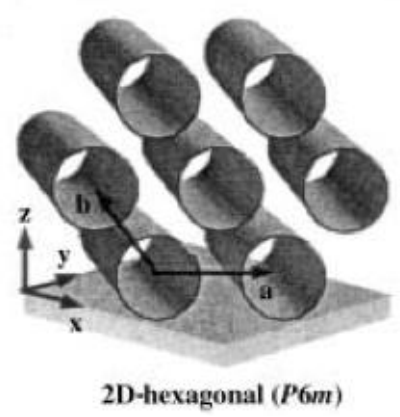

Figura 2.5: Arranjo estrutural de poros hexagonal da sílica SBA-15[7].

Para essa simetria temos:

$$
\frac{1}{d_{h k l}^{2}}=\frac{4}{3}\left(\frac{h^{2}+h k+k^{2}}{a^{2}}\right)+\frac{l^{2}}{c^{2}}
$$


onde $\mathrm{h}$, k e $\mathrm{l}$ correspondem aos índices de Miller dos planos cristalográficos, onde a e c são os parâmetros de rede. Como essa estrutura é bidimensional, o parâmetro $l=$ 0, logo o último termo se anula [4]. Nesse caso, temos também que:

$$
a=D+E
$$

onde D é o diâmetro dos poros e E é a espessura da parede.

Todos os experimentos de SAXS foram realizados no Laboratório de Cristalografia do Instituto de Física da USP (campus Butantã), no equipamento Nanostar da Bruker. As amostras foram medidas com intervalo de tempo de 3600 segundos.

\subsection{RBS (Rutherford Backscattering Spectroscopy)}

O RBS é um método de análise do tipo nuclear-espectroscópico, junto com o método PIXE (Proton Induced X-Ray Emission) são denominados métodos de análise de materiais por feixes iônicos, ou IBA (Ion Beam Analysis). Para a realização destes métodos são utilizado feixes de $\mathrm{H}^{+}, \mathrm{He}^{+}$ou $\mathrm{He}^{++}$.

As energias são da ordem de $\mathrm{MeV}$ e correntes da ordem de nA. A energia dos íons utilizada para incidir na amostra atinge profundidades da ordem de $\mu \mathrm{m}$.

Os métodos de PIXE e RBS são utilizados de forma complementar para identificar e quantificar os constituintes de uma amostra de forma elementar.

\subsubsection{Breve abordagem sobre RBS}

O RBS consiste em medir a energia de partículas de um feixe que colide com os átomos da amostra alvo que será analisada e sofreram retroespalhamento [30].

Durante as colisões ocorrem perdas de energia entre os íons incidentes e os átomos da amostra. A taxa de redução de energia de partícula espalhada (ou retroespalhada) é diretamente relacionada à razão entre as massas da partícula incidente e a do átomo alvo. Esta razão permite identificar qual a massa do átomo alvo e, consequentemente, qual seu elemento químico correspondente [30].

Identificando o átomo alvo é possível determinar, pela probabilidade de colisão entre as partículas incidentes e os átomos do alvo, a densidade do material dada em átomos $/ \mathrm{cm}^{2}$.

Determinada a probabilidade, é possível obter o número total de partículas detectadas (A), para um número de partículas incidentes (Q), medido pela corrente do feixe. 
A e Q são obtidos através da seção de choque de espalhamento. Segue abaixo um diagrama sobre o arranjo experimental [30] [29].

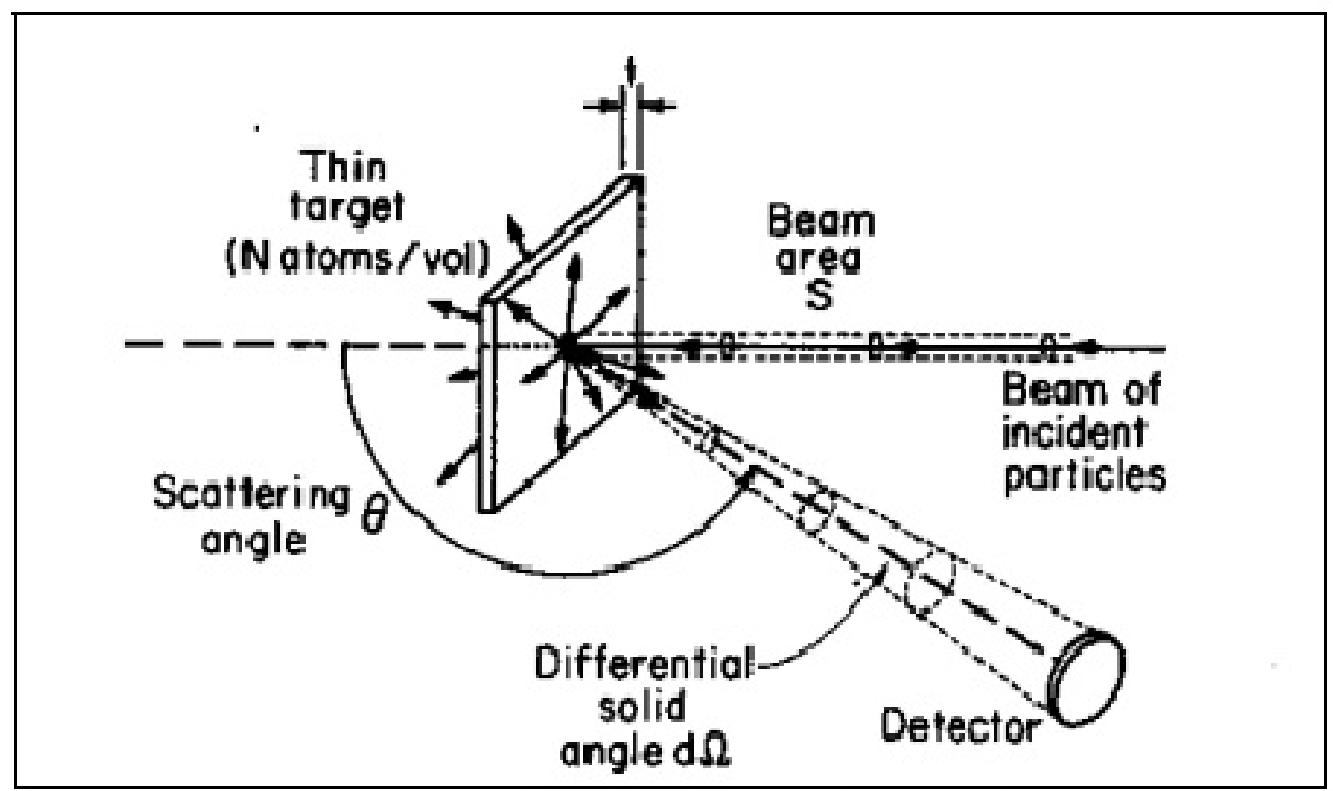

Figura 2.6: Diagrama de um arranjo experimental para experimento de RBS. [29]

Através da perda de energia da partícula durante seu trajeto dentro da amostra é possível obter a distância relativa percorrida com relação à superfície. Portanto, é possivel estabelecer uma escala de profundidade com a energia das partículas espalhadas. A energia de partícula espalhada pode depender da energia do feixe, da razão entre as massas da partícula incidente e a amostra alvo e do local onde ocorreu a colisão (superfície - maior energia, dentro do filme - menor energia).

Sendo assim, o RBS auxilia na determinação da composição de materiais.

\subsubsection{Interpretação e análise de um espectro de RBS}

Abaixo segue exemplo de como analisar o espectro de um filme de $\mathrm{SiO}_{2}$, com espessura $\mathrm{t}=300 \mathrm{~nm}$ sobre substrato de carbono figura 2.6.

$\mathrm{O}$ feixe com energia $\mathrm{E}_{0}$ incide sobre a amostra e é espalhado na superficie da amostra pelos átomos. A energia de espalhamento de átomos de $\mathrm{Si}$ é $\mathrm{K}_{S i} E_{0}$ e para o oxigênio é $\mathrm{K}_{O} \mathrm{E}_{0}$.

Quando o feixe atinge a interface com o substrato, sua energia é dada por $\mathrm{E}=\mathrm{E}_{0}-$ $\Delta E$.

Realizando uma primeira aproximação, $\Delta E$ pode ser calculado pela equação abaixo. 


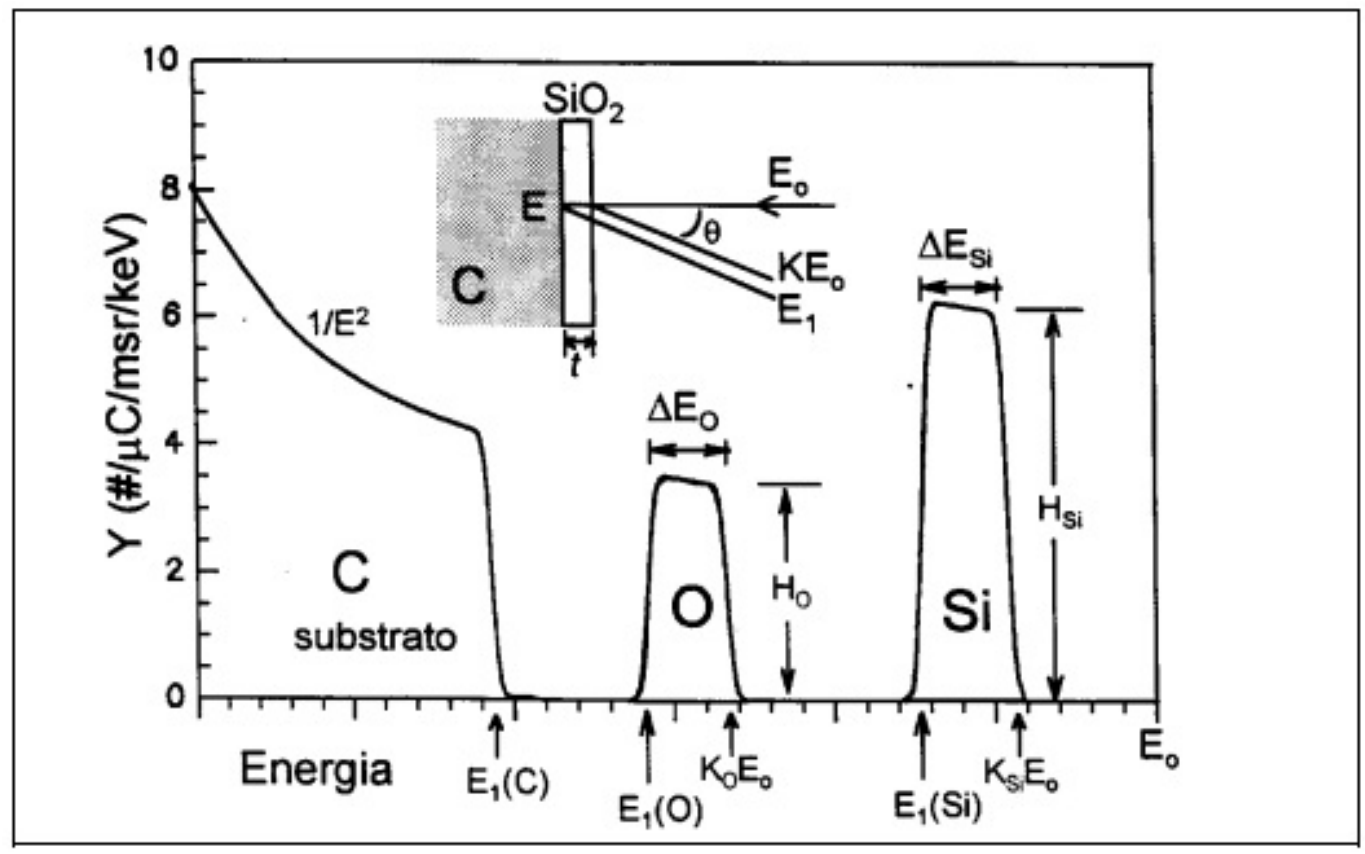

Figura 2.7: Espectro RBS de um filme de $\mathrm{SiO}_{2}$ sobre carbono. [29]

$$
\Delta E(t)=\int_{t} \frac{d E}{d x} d x \cong \frac{d E}{d x_{i}} t
$$

Agora é necessário determinar $\mathrm{dE} / \mathrm{dx}$ do filme para determinar a estequiometria da amostra. As partículas espalhadas emergem com sua energia específica, sendo freadas no seu caminho de saída do filme, rumo ao detetor, emergindo com as energias:

$$
E_{1}(C)=K_{C} E_{0}-[S] . t \quad E_{1}(O)=K_{O} E_{0}-[S] . t \quad E_{1}(S i)=K_{S i} E_{0}-[S] . t
$$

Em um filme fino, a largura dos picos elementares no espectro RBS é dada por:

$$
\Delta E_{0}=[S]_{O}^{\text {meio }} . t \quad \text { e } \quad \Delta E_{S i}=[S]_{S i}^{\text {meio }} . t
$$

Onde $[\mathrm{S}]_{y}$ do filme indica que no cálculo de $[\mathrm{S}]$ é utilizado o fator cinemático $\left(\mathrm{K}_{y}\right)$ e o poder de freamento do meio $\left(\mathrm{SiO}_{2}\right)$. 
As equações de 2.6 apresentam como obter a estequiometria do filme, restando apenas determinar o cálculo de [S].

A altura $\mathrm{H}_{k}$ das contagens do canal $\mathrm{k}$ do espectro é o número de eventos com energia entre $\mathrm{E}_{k}$ e $\mathrm{E}_{k}-\delta$.

A relação que permite relacionar cada canal com uma largura $\delta$ da amostra com espessura $\mathrm{x}=[\mathrm{S}] \delta$ é:

$$
\Delta E_{d}=K E_{0}-E_{1}=[S] . x
$$

Dessa forma, o número de eventos coletados $\mathrm{H}_{k}$ é função da espessura da fatia da amostra e do número de unidades espalhadoras (átomos de espécies i) na fatia. A equação 2.8 permite calcular $\mathrm{H}_{k}$ :

$$
H_{k}=\sigma_{i}\left(E_{k}\right) \cdot \Omega \cdot Q \cdot N_{i}\left(x_{i} / \cos \theta_{1}\right)
$$

Onde a espessura foi corrigida pelo fator $\left(\cos \theta_{1}\right)^{-1}$ devido ao ângulo de incidência não ser normal à superfície. Usando 2.7 e substituindo $\left[\mathrm{S}_{o}\right] / \mathrm{N}=\left[\varepsilon_{o}\right]$ assumindo válida a aproximação de superfície, temos:

$$
H_{k}=\sigma_{i} \cdot\left(E_{o}\right) \cdot \Omega \cdot Q \cdot n_{i}\left(\delta /\left(\left[\varepsilon_{o}\right]_{i}^{m e i o} \cos \theta_{1}\right)=H_{o}\right.
$$

A equação 2.10 mostra que a altura de um espectro de RBS no canal correspondente ao elemento i na superfície é diretamente proporcional a [29]:

a. Q: número total de partículas incidentes na amostra;

b. $\mathrm{n}_{i}=N_{i} / \mathrm{N}$ : fração atômica do elemento i na amostra cuja densidade atômica total vale $\mathrm{N}=\sum N_{i}$;

c. $\sigma\left(E_{o}\right)$ : seção de choque diferencial média calculada para o elemento i com o feixe com energia $E_{0}$;

d. $\Omega$ : ângulo sólido do detetor;

e. $\delta$ : a faixa de energia definida por um canal $(\mathrm{keV} / \mathrm{canal})$ que é determinada pela eletrônica;

f. $\left[\varepsilon_{o}\right]^{-1}$ : o inverso do fator de seção de choque e freamento;

g. $\left(\cos \theta_{1}\right)^{-1}$ : o inverso do ângulo de incidência do feixe na amostra em relação à normal.

Caso haja mais de um elemento na camada da superficie, cada um deles produzirá um sinal de superfície com altura $\mathrm{H}_{o} i$ na respectiva energia $\mathrm{E}=\mathrm{K}_{i} E_{0}$. 
No caso de dois elementos, $\mathrm{A}$ e $\mathrm{B}$, com densidades atômicas $\mathrm{n}_{A}$ e $\mathrm{n}_{B}$, temos:

$$
\left(\frac{H_{o A}}{H_{o B}}\right)=\frac{\sigma_{A}\left(E_{o}\right) n_{A}\left[\varepsilon_{o}\right]_{B}^{\text {meio }}}{\sigma_{B}\left(E_{o}\right) n_{B}\left[\varepsilon_{o}\right]_{A}^{\text {meio }}}
$$

Que nos permite obter a razão $\mathrm{n}_{A} / \mathrm{n}_{B}$ de concentrações atômicas. Em aproximação de ordem zero, pode-se supor $[\varepsilon]_{B} /[\varepsilon]_{A}=1$ e calcular $\left(\mathrm{n}_{A} / \mathrm{n}_{B}\right)_{o}$.

Com este valor é possivel estimar $[\varepsilon]_{B} /[\varepsilon]_{A}$ e refinar o cálculo de $\mathrm{n}_{A} / \mathrm{n}_{B}$. Uma única interação produz, em geral, resultados bastantes satisfatórios.

A razão $\mathrm{H}_{A} / \mathrm{H}_{B}$ independe da largura $\mathrm{x}_{i}$ e da densidade atômica do meio e depende apenas das frações atômicas dos elementos que compõem o filme 30] [29].

As medidas de RBS foram realizadas no LAMFI-USP (Laboratório de Análise de Materiais por Feixes Iônicos) com as seguintes condições: feixe de $\mathrm{He}^{+}$com energia de $2,2 \mathrm{MeV}$.

\subsection{Fotoluminescência (PL)}

As Terras Raras (TR) formam um grupo especial de elementos que incluem os lantanídeos. Os lantanídeos são caracterizados por conter a camada 4f preenchida de forma incompleta. Devido ao preenchimento incompleto da camada 4f, os lantanóides apresentam como característica bandas finas de absorção e emissão por apresentarem orbitais completos internos.

Atualmente, estes elementos fazem parte de um grande campo de aplicações, tais como: catalisadores [12]; materiais luminescentes, marcadores luminescentes para bioensaios, eletroluminescência, triboluminescência, etc [20] [9].

Os íons terras raras trivalentes $\left(\mathrm{TR}^{3+}\right)$ formam compostos com demais elementos químicos e, portanto, tornam-se capazes de emitir nas regiões espectrais: ultravioleta próximo $\left(\mathrm{Ce}^{3+}\right.$ e $\left.\mathrm{Gd}^{3+}\right)$, visível $\left(\right.$ azul $-\mathrm{Tm}^{3+}$; verde - $\mathrm{Tb}^{3+}$ e $\mathrm{Er}^{3+}$; amarelo - $\mathrm{Dy}^{3+}$; laranja - $\mathrm{Sm}^{3+}$ e vermelho - $\left.\mathrm{Eu}^{3+}\right)$ e no infravermelho próximo $\left(\mathrm{Nd}^{3+}, \mathrm{Er}^{3+}, \mathrm{Tm}^{3+} \mathrm{e}\right.$ $\left.\mathrm{Yb}^{3+}\right)[20]$ [13].

$\mathrm{O}$ aumento do número de pesquisas envolvendo íons terras raras deve-se à alta sensibilidade, tempo de resposta, flexibilidade e simplicidade na execução [11] [19]. Existem muitos estudos no desenvolvimento de partículas incorporando complexos de TR, tais como: partículas de latex, sílica, zircônia etc. [33].

Neste trabalho, foram utilizados os íons $\mathrm{Eu}^{3+}$, sob forma de nitrato, para obter um óxido incorporado em matriz de sílica mesoporosa ordenada (SBA-15).

\subsubsection{Espectroscopia eletrônica de terras raras}

Devido ao grande número de pesquisas envolvendo as propriedades luminescentes de complexos $\mathrm{TR}^{3+}$, a espectroscopia de luminescência desses íons torna-se extremamente 
importante.

A espectroscopia de luminescência está associada à exibição de bandas de emissão extremamente finas, oriundas das transiçoes intraconfiguracionais $4 \mathrm{f}-4 \mathrm{f}$ e tempo de vida longo, apresentando propriedades óticas singulares. A regra de Laporte proíbe transições por dipolo elétrico entre estados de mesma paridade $(\Delta l= \pm 1)$, por exemplo as transições $(4 f \rightarrow 4 f)$ para o íon livre $(\Delta l=0)$.

Quando um íon terra rara encontra-se na presença de um campo ligante cuja simetria não apresenta centro de inversão, esta regra pode ser alterada. Isso ocorre devido a distorção da simetria esférica do íon livre que acarreta em uma mistura de configurações eletrônicas de paridades opostas $\left(4 \mathrm{f}^{N}\right.$ e $\left.4 \mathrm{f}^{N-1} 5 \mathrm{~d}\right)$. Se a simetria do campo ligante apresentar centro de inversão à distorção ocorre, porém não acarreta em mistura de estados com paridades opostas, portanto, os estados resultantes continuam com paridades bem definidas e a regra de Laporte não é violada. O efeito de polarização dos ligantes tem se mostrado de grande importância para as transições 4f-4f [15] [22].

As propriedades luminescentes podem ser classificadas em quatro grupos diferentes [15] [14] [22].

1. Primeiro grupo: Íons que apresentam configuração com subcamada 4f cheia ou vazia não apresentam luminescência, pois não possuem elétrons oticamente ativos: $\mathrm{Sc}^{3+}\left(3 \mathrm{~d}^{0}\right), \mathrm{Y}^{3+}\left(4 \mathrm{~d}^{0}\right), \mathrm{La}^{3+}\left(4 \mathrm{f}^{0}\right)$ e $\mathrm{Lu}^{3+}\left(4 \mathrm{f}^{14}\right)$

2. Segundo grupo: Íon $\mathrm{Gd}^{3+}$ que possui subcamada $4 \mathrm{f}^{7}$ semipreenchida apresentando gap de energia. Nesse caso, o nível emissor do íon $\mathrm{Gd}^{3+}$ não aceita transferência de energia do estado excitado mais alto do ligante via transferência de energia intramolecular ligante-metal.

3. Terceiro grupo: Íons $\mathrm{Sm}^{3+}\left(4 \mathrm{f}^{5}\right), \mathrm{Eu}^{3+}\left(4 \mathrm{f}^{6}\right), \mathrm{Tb}^{3+}\left(4 \mathrm{f}^{8}\right)$ e $\mathrm{Dy}^{3+}\left(4 \mathrm{f}^{9}\right)$, constituem o grupo que apresenta gap de energia relativamente grande 2.1 entre os níveis do estado excitado e do estado fundamental. Os complexos contendo estes íons apresentam uma alta intensidade na luminescência via estado tripleto do ligante para o nível emissor do íon $\mathrm{TR}^{3+}$.

4. Quarto grupo: Íon $\mathrm{Ce}^{3+}\left(4 \mathrm{f}^{1}\right), \operatorname{Pr}^{3+}\left(4 \mathrm{f}^{2}\right), \mathrm{Nd}^{3+}\left(4 \mathrm{f}^{3}\right), \mathrm{Ho}^{3+}\left(4 \mathrm{f}^{10}\right), \mathrm{Er}^{3+}\left(4 \mathrm{f}^{11}\right)$, $\mathrm{Tm}^{3+}\left(4 \mathrm{f}^{12}\right)$ e $\mathrm{Yb}^{3+}\left(4 \mathrm{f}^{13}\right)$. Seus complexos apresentam apenas fraca intensidade de luminescência, devido à pequena separação dos níveis de energia entre o estado emissor e o estado fundamental. Isto favorece processos de decaimento não radiativos através do acoplamento com os modos vibracionais dos ligantes.

Segue abaixo a configuração dos íons terras raras trivalentes 2.1

As medidas de fotoluminescência foram realizadas no Instituto de Química da USP e Instituto de Química da UNESP (Campus Araraquara). Neste trabalho serão apre- 
Tabela 2.1: Propriedades Luminescentes de Íons Terras Raras [22]

\begin{tabular}{|c|c|c|c|c|c|}
\hline Elemento & $\begin{array}{l}\text { Configuração } \mathbf{T R}^{3+} \\
\text { (termo espectroscópico) }\end{array}$ & $\underset{\AA}{\text { Raio } \text { TR }^{3+}}$ & Transição & $\begin{array}{l}\lambda_{\text {em }} \\
(\mathrm{nm})\end{array}$ & $\begin{array}{c}\text { Gap energia* } \\
\left(\mathrm{cm}^{-1}\right)\end{array}$ \\
\hline${ }^{21} \mathrm{Sc}$ & {$[\mathrm{Ar}] 3 \mathrm{~d}^{0}\left({ }^{1} \mathrm{~S}_{0}\right)$} & 0,68 & - & - & - \\
\hline${ }^{39} \mathrm{Y}$ & {$[\mathrm{Kr}] 4 \mathrm{~d}^{0}\left({ }^{1} \mathrm{~S}_{0}\right)$} & 0,88 & - & - & - \\
\hline${ }^{57} \mathrm{La}$ & {$[\mathrm{Xe}] 4 \mathrm{f}^{0}\left({ }^{1} \mathrm{~S}_{0}\right)$} & 1,06 & - & - & - \\
\hline${ }^{58} \mathrm{Ce}$ & {$[\mathrm{Xe}] 4 \mathrm{f}^{1}\left({ }^{2} \mathrm{~F}_{5 / 2}\right)$} & 1,03 & $5 \mathrm{~d} \rightarrow{ }^{2} \mathrm{~F}_{5 / 2}$ & - & - \\
\hline${ }^{59} \mathrm{Pr}$ & {$[\mathrm{Xe}] 4 \mathrm{f}^{2}\left({ }^{3} \mathrm{H}_{4}\right)$} & 1,01 & ${ }^{3} \mathrm{P}_{0} \rightarrow{ }^{3} \mathrm{H}_{6}$ & 610 & 3910 \\
\hline & & & ${ }^{1} \mathrm{D}_{2} \rightarrow{ }^{3} \mathrm{~F}_{4}$ & 1000 & 6940 \\
\hline & & & ${ }^{1} \mathrm{G}_{4} \rightarrow{ }^{3} \mathrm{H}_{5}$ & 1300 & - \\
\hline${ }^{60} \mathrm{Nd}$ & {$[\mathrm{Xe}] 4 \mathrm{f}^{3}\left({ }^{4} \mathrm{I}_{9 / 2}\right)$} & 0,99 & ${ }^{4} \mathrm{~F}_{3 / 2} \rightarrow{ }^{4} \mathrm{I}_{9 / 2}$ & 1060 & 5400 \\
\hline${ }^{61} \mathrm{Pm}$ & {$[\mathrm{Xe}] 4 \mathrm{f}^{4}\left({ }^{5} \mathrm{I}_{4}\right)$} & 0,98 & ${ }^{5} \mathrm{~F}_{1} \rightarrow{ }^{5} \mathrm{I}_{J}$ & 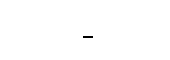 & - \\
\hline${ }^{62} \mathrm{Sm}$ & {$[\mathrm{Xe}] 4 \mathrm{f}^{5}\left({ }^{6} \mathrm{H}_{5 / 2}\right)$} & 0,96 & ${ }^{4} \mathrm{G}_{5 / 2} \rightarrow{ }^{6} \mathrm{H}_{9 / 2}$ & 590 & 7400 \\
\hline${ }^{63} \mathrm{Eu}$ & {$[\mathrm{Xe}] 4 \mathrm{f}^{6}\left({ }^{7} \mathrm{~F}_{0}\right)$} & 0,95 & ${ }^{5} \mathrm{D}_{0} \rightarrow{ }^{7} \mathrm{~F}_{2}$ & 615 & 12300 \\
\hline${ }^{64} \mathrm{Gd}$ & {$[\mathrm{Xe}] 4 \mathrm{f}^{7}\left({ }^{8} \mathrm{~S}_{7 / 2}\right)$} & 0,94 & ${ }^{6} \mathrm{P}_{7 / 2} \rightarrow{ }^{8} \mathrm{~S}_{0}$ & 311 & 32100 \\
\hline${ }^{65} \mathrm{~Tb}$ & {$[\mathrm{Xe}] 4 \mathrm{f}^{8}\left({ }^{7} \mathrm{~F}_{6}\right)$} & 0,92 & ${ }^{5} \mathrm{D}_{4} \rightarrow{ }^{7} \mathrm{~F}_{5}$ & 550 & 14800 \\
\hline${ }^{66} \mathrm{Dy}$ & {$[\mathrm{Xe}] 4 \mathrm{f}^{9}\left({ }^{6} \mathrm{H}_{15 / 2}\right)$} & 0,91 & ${ }^{4} \mathrm{~F}_{9 / 2} \rightarrow{ }^{6} \mathrm{H}_{13 / 2}$ & 570 & 7850 \\
\hline${ }^{67} \mathrm{Ho}$ & {$[\mathrm{Xe}] 4 \mathrm{f}^{10}\left({ }^{5} \mathrm{I}_{8}\right)$} & 0,89 & ${ }^{5} \mathrm{~F}_{5} \rightarrow{ }^{5} \mathrm{I}_{7,6}$ & 970,1450 & 3000 \\
\hline & & & ${ }^{5} \mathrm{~S}_{2} \rightarrow{ }^{5} \mathrm{I}_{8}$ & 550 & 2200 \\
\hline${ }^{68} \mathrm{Er}$ & {$[\mathrm{Xe}] 4 \mathrm{f}^{11}\left({ }^{4} \mathrm{I}_{15 / 2}\right)$} & 0,88 & ${ }^{4} \mathrm{~S}_{3 / 2} \rightarrow{ }^{4} \mathrm{I}_{15 / 2}$ & 545 & 3100 \\
\hline & & & ${ }^{4} \mathrm{I}_{13 / 2} \rightarrow{ }^{4} \mathrm{I}_{15 / 2}$ & 1500 & 6500 \\
\hline${ }^{69} \mathrm{Tm}$ & {$[\mathrm{Xe}] 4 \mathrm{f}^{12}\left({ }^{3} \mathrm{H}_{6}\right)$} & 0,87 & ${ }^{1} \mathrm{G}_{4} \rightarrow{ }^{3} \mathrm{H}_{6}$ & 480 & 6250 \\
\hline${ }^{70} \mathrm{Yb}$ & {$[\mathrm{Xe}] 4 \mathrm{f}^{13}\left({ }^{2} \mathrm{~F}_{7 / 2}\right)$} & 0,86 & ${ }^{3} \mathrm{~F}_{5 / 2} \rightarrow{ }^{2} \mathrm{~F}_{7 / 2}$ & 980 & 10250 \\
\hline${ }^{71} \mathrm{Lu}$ & {$[\mathrm{Xe}] 4 \mathrm{f}^{14}\left({ }^{1} \mathrm{~S}_{0}\right)$} & 0,85 & - & - & - \\
\hline
\end{tabular}

sentados os resultados obtidos no IQUSP utilizando o espectrofluorímetro SPEX1934D controlado pelo programa computacional DM3000F.

\subsection{Técnicas Complementares}

\subsubsection{Microscopia Eletrônica de Varredura (MEV)}

A Microscopia Eletrônica de Varredura é uma técnica muito utilizada para fornecer informações sobre a morfologia de amostras sólidas.

A principal razão da utilização do $\mathrm{MEV}$ é a alta resolução que pode ser obtida, 
permitindo analisar características micro e, até, nanoestruturais. Devido à forma como as imagens são criadas, imagens de MEV apresentam aparência tridimensional.

O equipamento utilizado para obtenção das imagens foi o JEOL JSM-7401F pertencente a Central Analítica do Instituto de Química da USP (campus Butantã).

\subsubsection{Isotermas de Adsorção-Dessorção de Nitrogênio (NAI)}

Adsorção é um processo onde moléculas de um gás ou de uma solução ligam-se numa camada densa sobre uma superfície sólida ou líquido. O processo em que as moléculas do gás se ligam à superfície é chamado de adsorção e a remoção dessas moléculas da superfície é chamado de dessorção.

O método de adsorção de gases permite obter a área superficial de um material poroso, a partir do método Brunauer-Emmet-Teller (BET)[7]; e a distribuição de tamanhos de poros é calculada pelo método Barrett-Joyner-Halenda (BJH) 28] [1] 24]

A isoterma de adsorção é obtida através da quantidade de gás adsorvido por um determinado adsorvente a uma temperatura fixa, esta quantidade de gás adsorvido depende dos valores de temperatura, pressão e composição do gás.

Isotermas de adsorção em materiais com alta porosidade são diferentes das isotermas de materiais maciços, devido a efeitos de capilaridade. O comportamento das isotermas pode ser classificado em vários tipos, de acordo com a figura 2.8(a).

- I: a quantidade de gás adsorvido aumenta com o aumento da pressão. Característica de materiais que possuem poros muito pequenos (microporosos) e que se enchem rapidamente.

- II: quantidade adsorvida aumenta com o aumento da pressão, alcança um patamar e aumenta com pressões altas. Característica de materiais que possuem baixa porosidade ou poros muito grandes.

- III: inicialmente apresenta pouca adsorção, mas uma vez que uma pequena gota ou "região de núcleos adsorventes" é formada na superfície a adsorção ocorre mais facilmente.

- IV e V: ocorrem quando multicamadas de gás são adsorvidos num sólido poroso. Inicialmente, a adsorção parece com o tipo II e III, mas eventualmente a camada adsorvida aumenta de forma que os poros ficam preenchidos, como resultado não há mais adsorção e a curva satura.

- Tipo VI (isoterma em degraus) ocorre em superfícies uniformes não porosas e representa uma adsorção camada a camada. A altura do degrau corresponde à capacidade de adsorção da monocamada em cada camada adsorvida. 

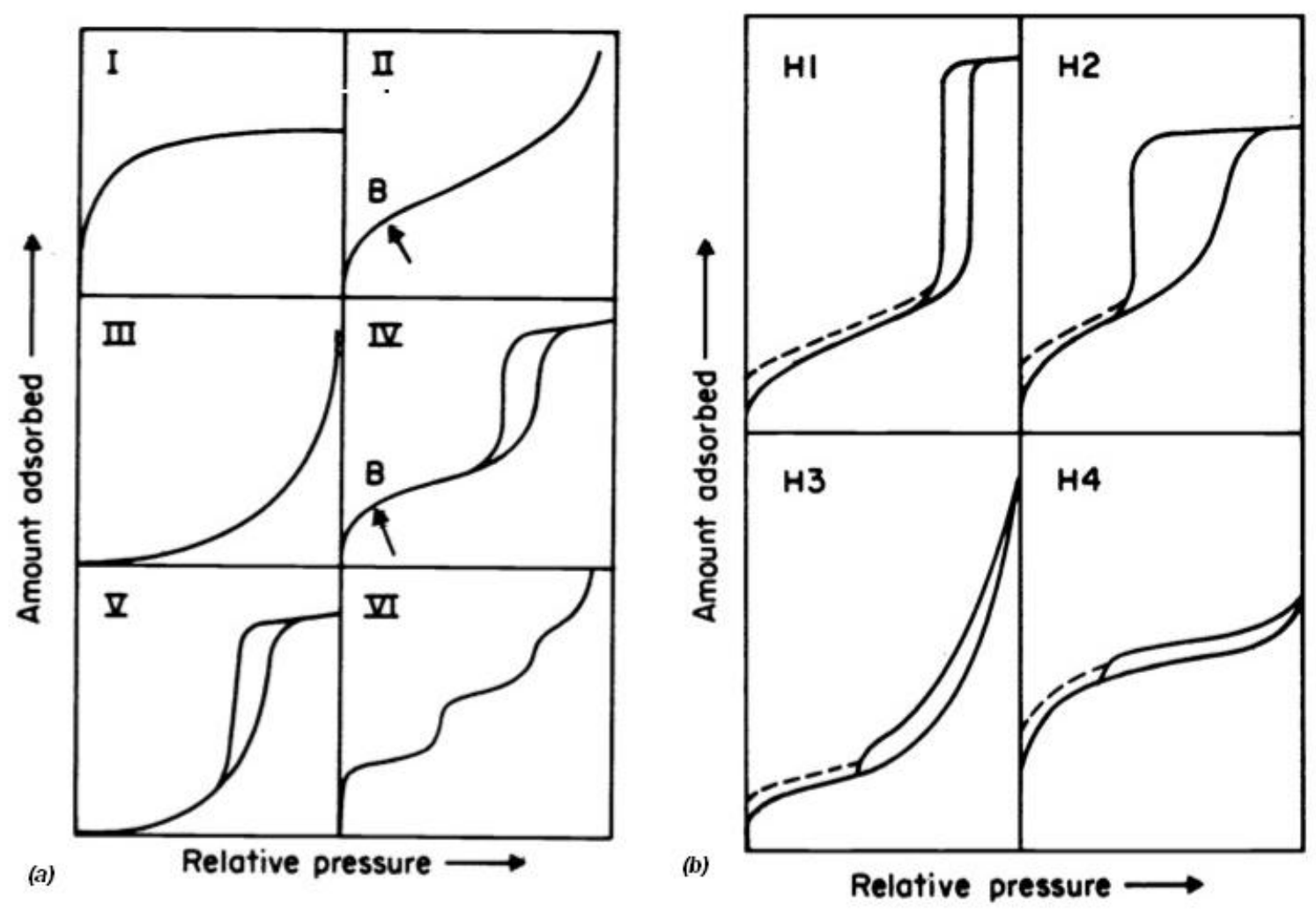

Figura 2.8: (a) Representação dos tipos de isotermas de adsorção descritos por Brunauer; (b) Representação dos tipos de histereses em isotermas de adsorção-dessorção [3].

O fenômeno da histerese, nas isotermas de adsorção, está associado ao fenômeno da condensação capilar em estruturas porosas. A curva de adsorção não coincide com a curva de dessorção, isto é, não há reversibilidade, como indicado na figura 2.8(b) para as isotermas do tipo IV e V. As histereses são classificadas segundo a IUPAC em:

- Tipo $\mathrm{H}_{1}$ : dois ramos da isoterma quase verticais e paralelos durante uma extensa gama de valores em relação à quantidade adsorvida. Associada a materiais porosos constituídos por partículas esféricas de tamanho uniforme ordenadas regularmente, resultando numa estreita distribuição de tamanho de poros.

- Tipo $\mathrm{H}_{2}$ : a dessorção é praticamente vertical com distribuição de tamanhos e formato de poros bem definida. Por vezes associa-se este tipo de histerese aos diferentes mecanismos de condensação e evaporação para poros em forma de gargalo. 
- Tipo $\mathrm{H}_{3}$ : dois ramos da isoterma assintóticos relativamente à vertical $\mathrm{P} / \mathrm{P}_{0}=1$. Associado a partículas lamelares que originam poros em formato de fenda.

- Tipo $\mathrm{H}_{4}$ : dois ramos da isoterma quase horizontais e paralelos durante uma extensa gama de valores de pressão relativa. Associado a materiais com poros estreitos em forma de fenda, mas juntamente com o aspecto da isoterma do tipo I indica a presença de microporos [28, 25].

O método BET calcula a área superficial através de um ajuste linear da medida da adsorção de um gás conhecendo-se a área ocupada pela molécula desse gás, de forma a determinar a quantidade adsorvida pela amostra a ser analisada quando se atinge o equilíbrio para cada valor de pressão. Essa medida é feita em condições normais de temperatura e pressão 27.

O método BJH é baseado no modelo de condensação capilar desenvolvido por Cohan (1938) [25]. Esse método é utilizado para avaliar a distribuição de tamanho de poros de um sólido poroso através da adsorção ou dessorção de gases. Os cálculos são feitos com base na isoterma de adsorção usando os seguintes dados: pressão relativa e volume de adsorbato correspondente e a espessura da camada adsorvida [10.

As medidas de adsorção-dessorção foram realizadas no Laboratório de Cristalografia (LCr), utilizando o equipamento ASAP 2020 da Micromeritics. Todas as amostras foram medidas a temperatura de $77 \mathrm{~K}$ em banho de $\mathrm{N}_{2} l$ Foram obtidos resultados de distribuição de tamanho de poros, área superficial e volume de poros das amostras. 


\section{Capítulo 3}

\section{Amostras preparadas: resultados e discussão}

\subsection{Introdução}

As sínteses preparadas e apresentadas neste trabalho têm como objetivo produzir SBA-15 luminescente através de um único processo, denominado one pot synthesis. Para a incorporação do precursor, sob a forma de nitrato de európio hexa-hidratado, utilizou-se a concentração nominal de $10 \mathrm{~mol} \%$ do precursor de terra rara (ou Eu) em relação à matriz de sílica $\left(\mathrm{SiO}_{2}\right)$. Segue abaixo o processo de preparação da SBA-15:

Durante a execução do projeto, a incorporação do precursor luminescente foi testada de três formas:

- logo após a incorporação do TEOS;

- após $12 \mathrm{~h}$ de agitação magnética a $40^{\circ} \mathrm{C}$, o precursor é adicionado e a solução permanece mais $12 \mathrm{~h}$ sob agitação

- ao final da síntese.

Após análise de resultados de luminescência dos três tipos de síntese, a amostra que apresentou maior intensidade de luminescência corresponde à síntese com incorporação do precursor luminescente após $12 \mathrm{~h}$ de agitação magnética a $40^{\circ} \mathrm{C}$ da solução contendo apenas a fonte de silício (TEOS).

No processo de síntese foi avaliado o efeito da remoção do sobrenadante nas propriedades do material. O sobrenadante é formado após o tratamento hidrotérmico em auto-clave da solução de precursores. Também foi avaliado o efeito de um processo de repouso desta solução por um período de $48 \mathrm{~h}$. As amostras foram nomeadas da seguinte forma: cscr (com sobrenadante, com repouso), cssr (com sobrenadante, sem repouso), sscr (sem sobrenadante, com repouso) e sssr (sem sobrenadante, sem repouso). 
Após a preparação das amostras, uma parte do material foi separada para ser calcinada, para total remoção do polímero. O processo de calcinação é realizado da seguinte forma: aquecimento até $540^{\circ} \mathrm{C}$, a $2^{\circ} \mathrm{C} / \mathrm{min}$ em atmosfera de $\mathrm{N}_{2}$, atingindo a temperatura de $540^{\circ} \mathrm{C}$. Em seguida, o material permanece mais $6 \mathrm{~h}$ em tratamento térmico à temperatura constante em atmosferas de $\mathrm{N}_{2}(2 \mathrm{~h})$ e ar (4h).

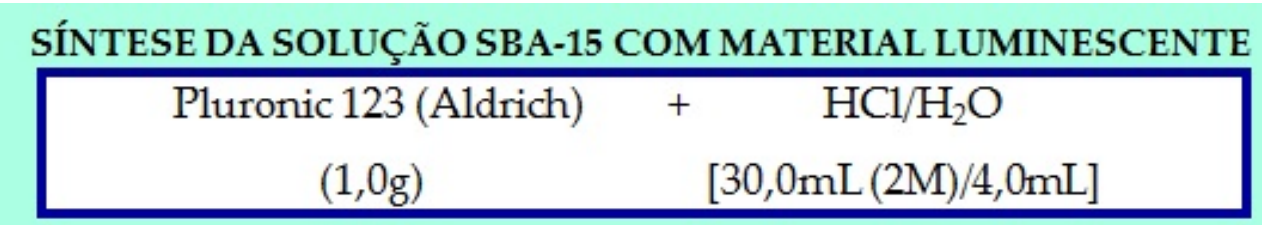

Agitação magnética por $2 \mathrm{~h}$ a $40^{\circ} \mathrm{C}$

TEOS(Tetraetilortosilicato) - 2,23mL

Agitação magnética por $12 \mathrm{~h}$ a $40^{\circ} \mathrm{C}$

Incorporação do material luminescente

Agitacão magnética por $12 \mathrm{~h}$ a $40^{\circ} \mathrm{C}$.

O material obtido é colocado em uma aut ${ }^{2}$ ve por $48 \mathrm{~h}$ a $100^{\circ} \mathrm{C}$.

Secagem a $100^{\circ} \mathrm{C}$ por 24 horas

Calcinação a $540^{\circ} \mathrm{C}$ a $2^{\circ} \mathrm{C} / \mathrm{min}$ em $\mathrm{N}_{2}$

(Patamara $540^{\circ} \mathrm{C}: 2 \mathrm{~h}$ de $\mathrm{N}_{2}+2 \mathrm{~h}$ em ar)

Figura 3.1: Diagrama esquemático de síntese de SBA-15 com material luminescente. 
As amostras foram denominadas da seguinte forma:

Tabela 3.1: Amostras preparadas.

\begin{tabular}{cc}
\hline Eu & SBA \\
\hline A - Eusssr & E- SBAcssr \\
\hline B - Eucssr & F - SBAsssr \\
\hline C - Eucscr & G - SBAcscr \\
\hline D - Eusscr & H - SBAsscr \\
\hline
\end{tabular}

As amostras que podem ser comparadas são as seguintes:

Tabela 3.2: Amostras que podem ser comparadas.

\begin{tabular}{cc}
\hline $\mathrm{A}$ & $\mathrm{F}$ \\
\hline $\mathrm{B}$ & $\mathrm{E}$ \\
\hline $\mathrm{C}$ & $\mathrm{G}$ \\
\hline $\mathrm{D}$ & $\mathrm{H}$ \\
\hline
\end{tabular}

\subsection{Sínteses das amostras}

Durante a execução do projeto, vários valores de concentração de precursor foram testados. Como forma de verificar se o precursor luminescente permanecia agregado à matriz de sílica após passar pelo processo de calcinação, medidas de RBS eram realizadas como forma de quantificar a concentração de precursor de terra rara na matriz de sílica. Dadas as variações encontradas, revisitamos a forma como as sínteses foram elaboradas e decidiu-se estabelecer controles ao longo do processo para poder estabelecer qual a melhor forma de se obter um material mesoporoso ordenado luminescente. Os controles escolhidos para elaborar um padrão de comparação foram o processo de repouso e permanência do sobrenadante. Ou seja, verificou-se que a maior intensidade de luminescência é obtida para amostras que permaneceram em repouso e que não foi removido o sobrenadante da síntese.

\subsubsection{Com e sem repouso após tratamento térmico}

De acordo com o processo de síntese deste trabalho, após o período de agitação por 24h, a solução é transferida para uma autoclave de teflon e é levada para tratamento 
térmico em estufa por $48 \mathrm{~h}$ a uma temperatura $\mathrm{T}=100^{\circ} \mathrm{C}$. Para estabelecer um padrâo sobre a influência do período de repouso da amostra em autoclave, após o período de $48 \mathrm{~h}$ de tratamento, um grupo de amostras contendo Eu na matriz da SBA-15 e outro grupo contendo apenas SBA-15 foi preparado, nas mesmas condições. Metade destes materiais passou por período de repouso em autoclave por mais $48 \mathrm{~h}$ à temperatura ambiente. O efeito do repouso foi estudado para averiguar se haveria a possibilidade do precursor luminescente ser diluído no sobrenadante e, por consequência, diminuir a concentração nominal de precursor na matriz de sílica. Outro efeito avaliado foi o da possibilidade de aumento da área superficial do material devido ao maior tempo de repouso e possibilidade de maior agregação da sílica. Os resultados do efeito do repouso serão abordados na próxima seção.

\subsubsection{Com e sem sobrenadante}

Outra forma de verificar se o material luminescente pode solubilizar no sobrenadante com $\mathrm{HCl}$ e $\mathrm{H}_{2} \mathrm{O}$ presente na autoclave, um grupo de amostras contendo Eu na matriz da SBA-15 e outro grupo contendo apenas SBA-15 foram preparados, nas mesmas condições. Metade destes materiais teve seu sobrenadante removido, restando apenas o corpo de fundo e a outra metade teve seu sobrenadante mantido. As amostras com e sem sobrenadante foram secas em estufa a uma temperatura de $70^{\circ} \mathrm{C}$. Durante a secagem das amostras, foi observado que o tempo para a secagem das amostras contendo sobrenadante foi maior e seu aspecto físico era diferente quando comparado às amostras sem sobrenadante.

\subsection{Resultados}

\subsubsection{SAXS}

Os resultados de SAXS foram obtidos através das seguintes condições:

Tabela 3.3: Condições de medida.

Equipamento Nanostar

$=3600$ segundos 


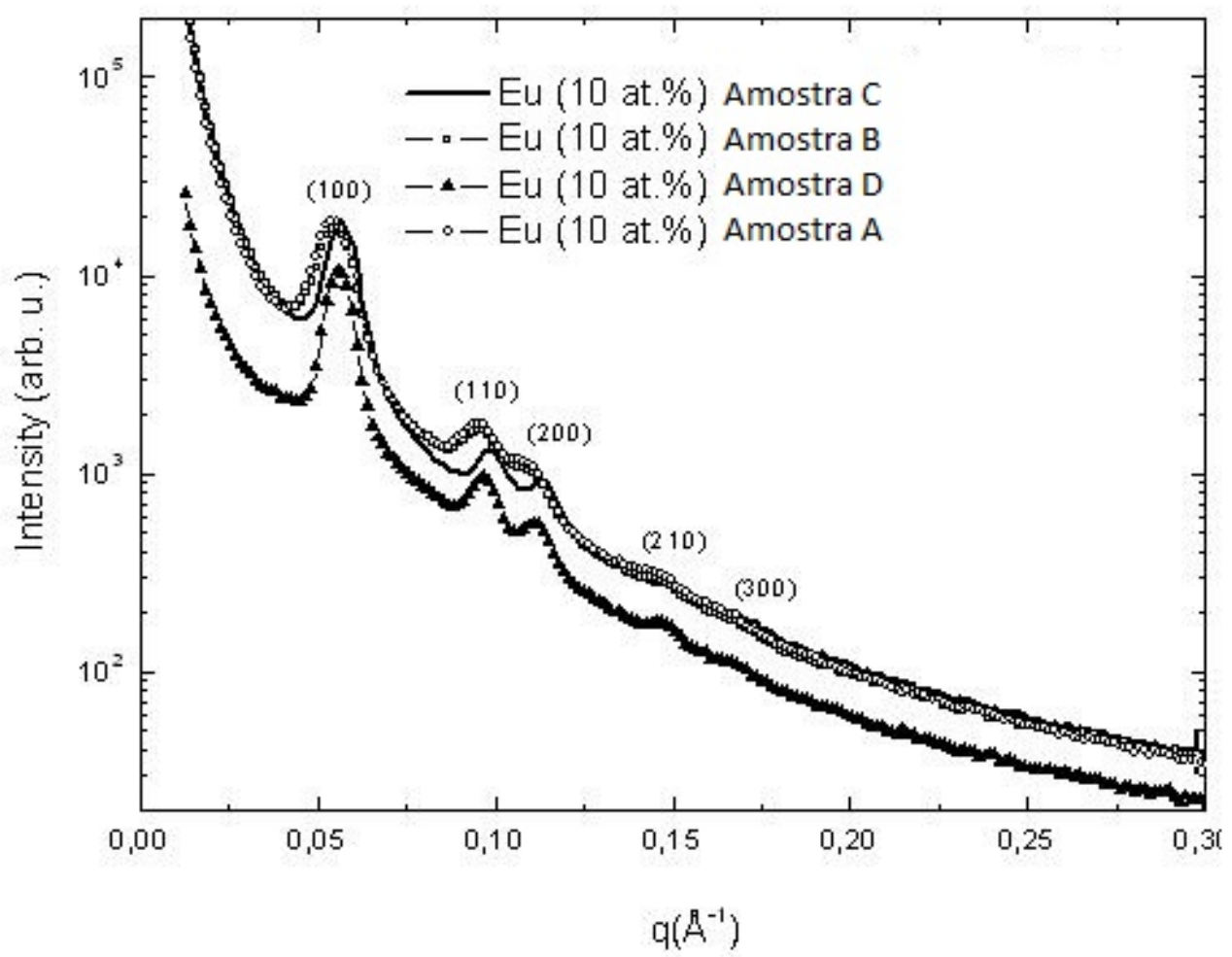

Figura 3.2: Espalhamento de raios $\mathrm{X}$ a baixo ângulo das amostras contendo európio.

Tabela 3.4: Resultados das amostras com Eu.

\begin{tabular}{lc}
\hline & a (parâmetro de rede $(\mathrm{nm})$ \\
\hline $\mathrm{A}$ & $11,6 \mathrm{~nm}$ \\
\hline $\mathrm{B}$ & $11,6 \mathrm{~nm}$ \\
\hline $\mathrm{C}$ & $11,0 \mathrm{~nm}$ \\
\hline $\mathrm{D}$ & $11,2 \mathrm{~nm}$ \\
\hline
\end{tabular}




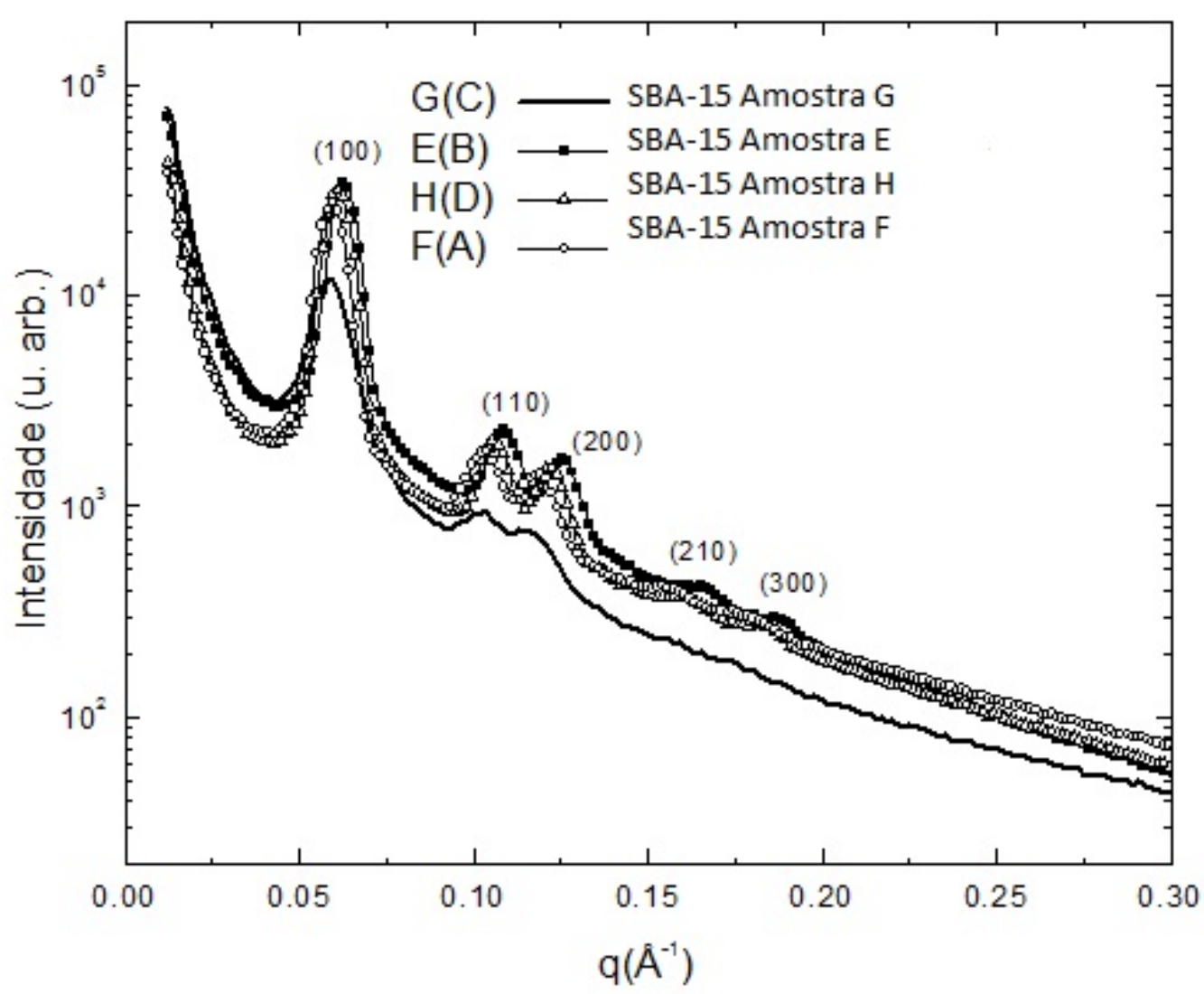

Figura 3.3: Espalhamento de raios $\mathrm{X}$ a baixo ângulo das amostras contendo SBA-15 pura.

Tabela 3.5: Resultados das amostras de SBA-15 pura.

\begin{tabular}{lc}
\hline & a (parâmetro de rede $(\mathrm{nm})$ \\
\hline $\mathrm{E}$ & $10,0 \mathrm{~nm}$ \\
\hline $\mathrm{F}$ & $10,5 \mathrm{~nm}$ \\
\hline $\mathrm{G}$ & $10,5 \mathrm{~nm}$ \\
\hline $\mathrm{H}$ & $10,3 \mathrm{~nm}$ \\
\hline
\end{tabular}


Comparando os resultados de SAXS das amostras analisadas, podemos concluir:

- A e B: possuem uma estrutura ordenada idêntica, com maior parâmetro de rede comparado às amostras com repouso $(\mathrm{C}$ e $\mathrm{D})$, que possuem parâmetros de rede similares. Há indicações que as paredes são corroídas durante o processo de repouso, pois há uma diminuição na área superficial e volume de microporos.

- D: amostra mais similar à estrutura da SBA-15 (H), o que indica uma remoção de Eu da matriz ou uma localização em parede diferenciada. Os resultados de SAXS são consistentes com os de NAI, pois sua isoterma é mais similar à da SBA-15.

- À exceção da amostra G, os resultados de SAXS das amostras de SBA-15 são similares. A amostra G apresenta uma curva de SAXS consistente com o resultado de NAI, visto que a isoterma possui um ramo de poros pequenos na forma de fenda, conforme será apresentado adiante. Este resultado pode ser atribuído ao processo de repouso em solução ácida do sobrenadante, ocasionando a corrosão das paredes de sílica, destruindo parte da estrutura ordenada de poros cilíndricos.

- Os resultados de SAXS serão comparados com os de SEM para identificar eventuais mudanças morfológicas.

\subsubsection{Luminescência}

\subsubsection{Amostras contendo Európio}

As medidas de fotoluminescência apresentadas das amostras aquecidas até $650^{\circ} \mathrm{C}$ foram realizadas no Instituto de Química da USP (Campus Butantan), já as amostras aquecidas até $900^{\circ} \mathrm{C}$, para eliminar totalmente quaisquer produtos derivados de carbono que pudessem interferir na intensidade de luminescência, foram realizadas no Instituto de Química da UNESP (Campus Araraquara). Abaixo serão apresentados três gráficos correspondentes a emissão, excitação e tempo de vida das amostras com tratamento térmico até $650^{\circ} \mathrm{C}$ e $900^{\circ} \mathrm{C}$ :

Para as amostras com tratamento até $650^{\circ} \mathrm{C}$, as condições de medida utilizadas foram: 
Tabela 3.6: Parâmetros utilizados.

\begin{tabular}{ccc}
\hline Amostras & Excitação & Emissão \\
\hline $\mathrm{A}$ & $\lambda_{e m}=617 \mathrm{~nm}$ & $\lambda_{e x c}=393 \mathrm{~nm}$ \\
\hline $\mathrm{B}$ & $\lambda_{e m}=617 \mathrm{~nm}$ & $\lambda_{e x c}=393 \mathrm{~nm}$ \\
\hline $\mathrm{C}$ & $\lambda_{e m}=614,2 \mathrm{~nm}$ & $\lambda_{e x c}=393 \mathrm{~nm}$ \\
\hline $\mathrm{D}$ & $\lambda_{e m}=617,4 \mathrm{~nm}$ & $\lambda_{e x c}=393 \mathrm{~nm}$ \\
\hline $\mathrm{E}$ & $\lambda_{e m}=617,4 \mathrm{~nm}$ & $\lambda_{e x c}=393 \mathrm{~nm}$ \\
\hline $\mathrm{F}$ & $\lambda_{e m}=617,4 \mathrm{~nm}$ & $\lambda_{e x c}=393 \mathrm{~nm}$ \\
\hline $\mathrm{G}$ & $\lambda_{e m}=617,4 \mathrm{~nm}$ & $\lambda_{e x c}=393 \mathrm{~nm}$ \\
\hline $\mathrm{H}$ & $\lambda_{e m}=617,4 \mathrm{~nm}$ & $\lambda_{e x c}=393 \mathrm{~nm}$ \\
\hline
\end{tabular}

Resultados das amostras até $650^{\circ} \mathrm{C}$ :

- Efeito do repouso nas amostras A, B, C e D:

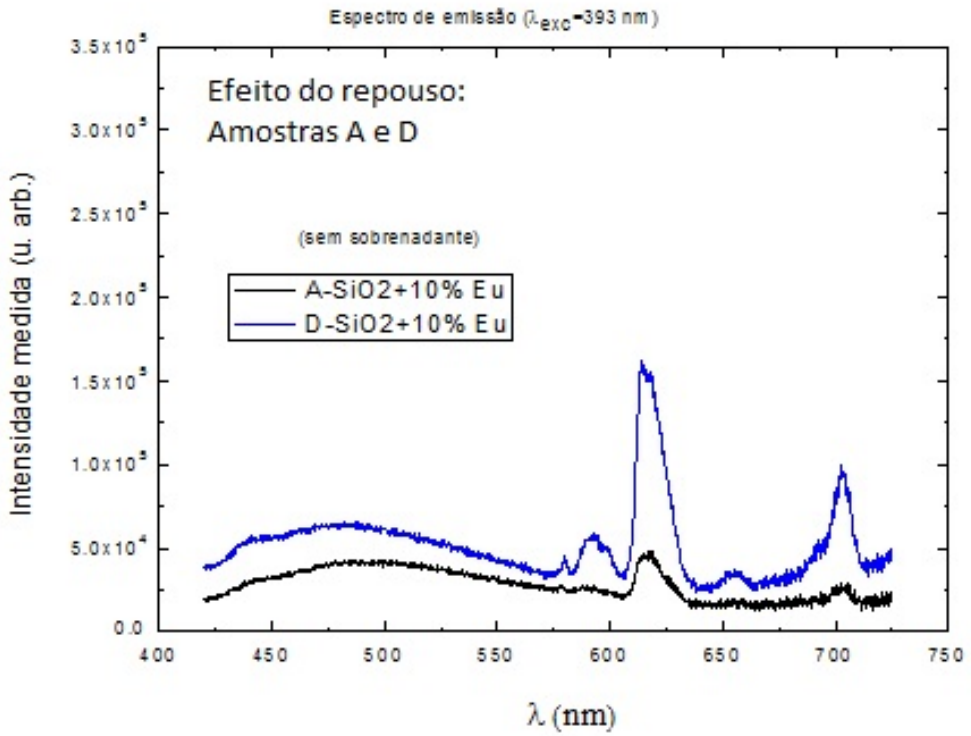

Figura 3.4: Espectro de luminescência das amostras A e D. 


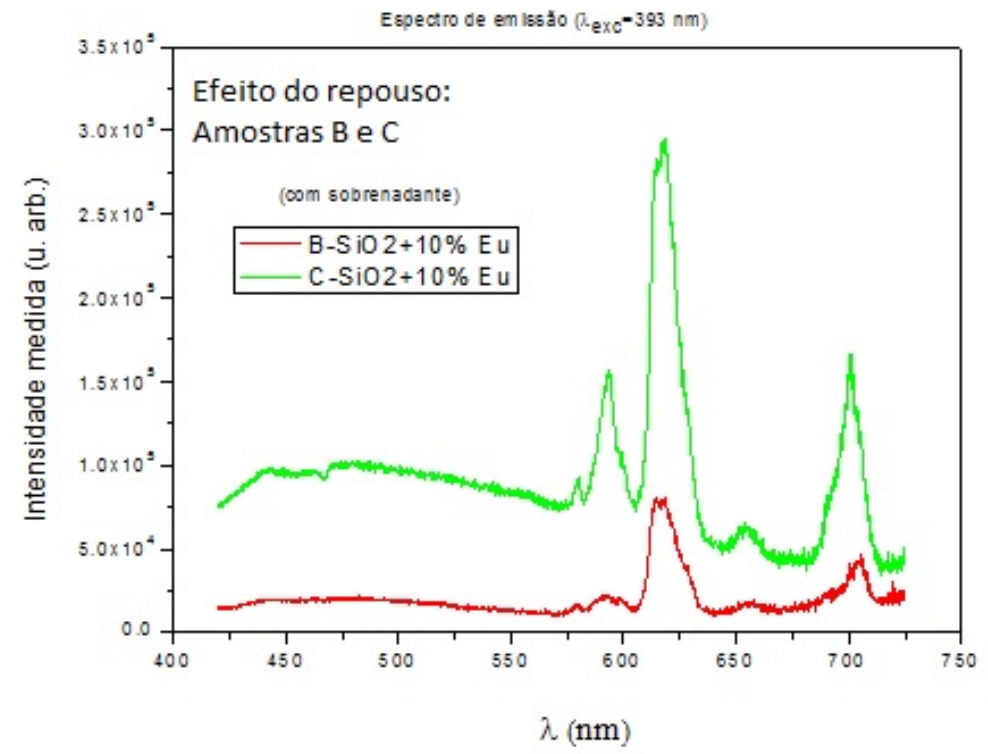

Figura 3.5: Espectro de luminescência das amostras B e C.

- Efeito do sobrenadante nas amostras A, B, C e D:

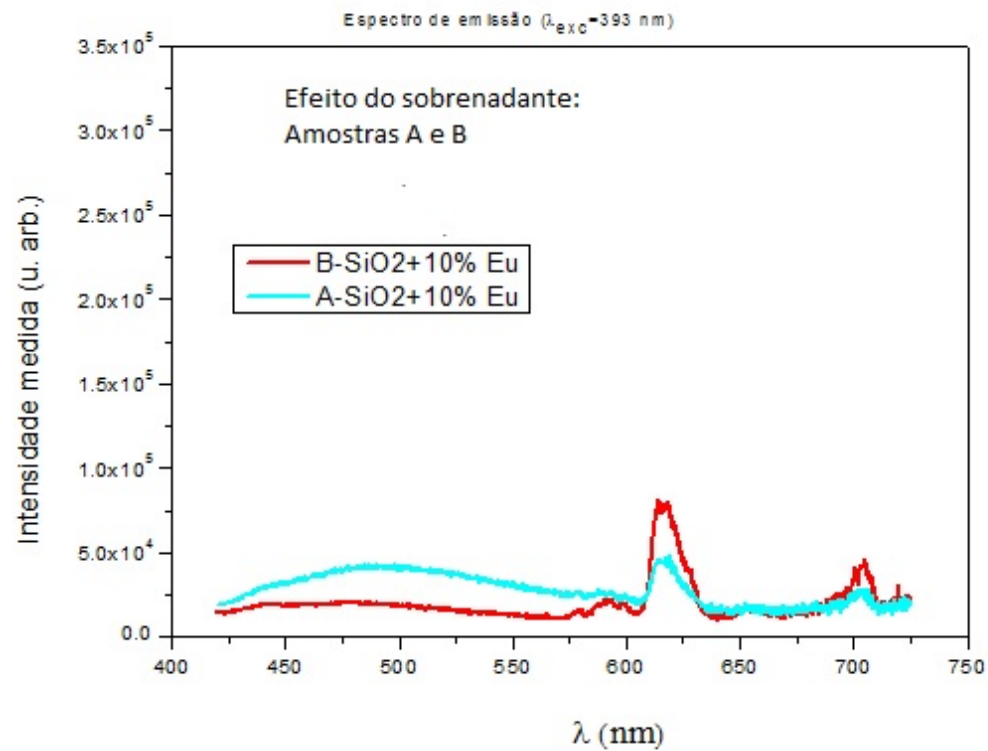

Figura 3.6: Espectro de luminescência das amostras A e B. 


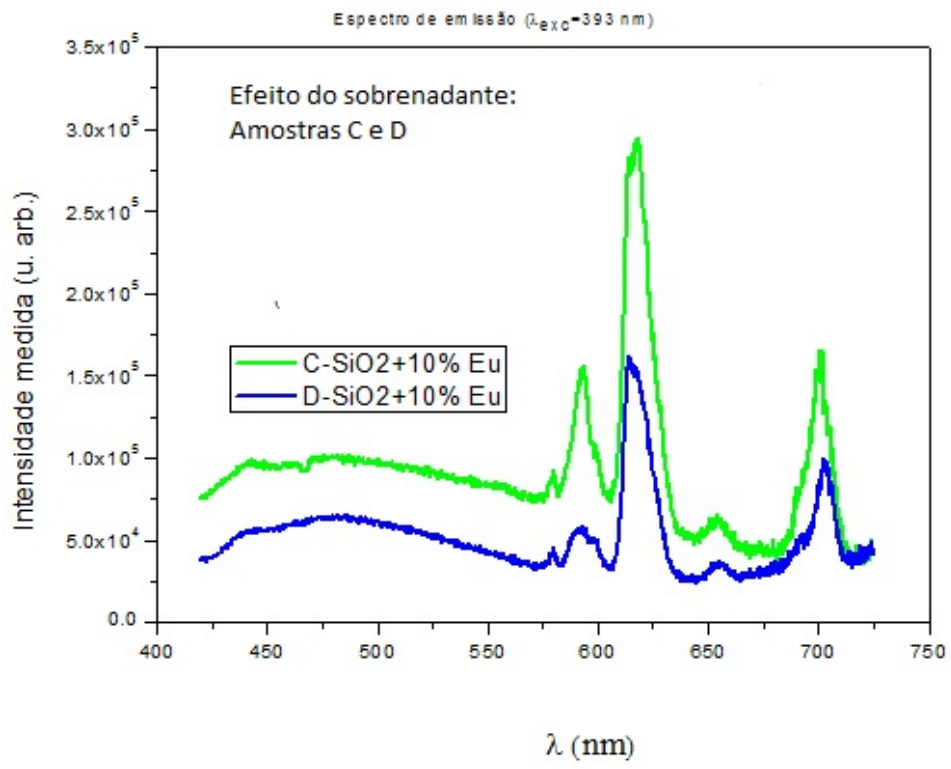

Figura 3.7: Espectro de luminescência das amostras C e D. 
Resultados de luminescência e tempo de vida para todas as amostras:

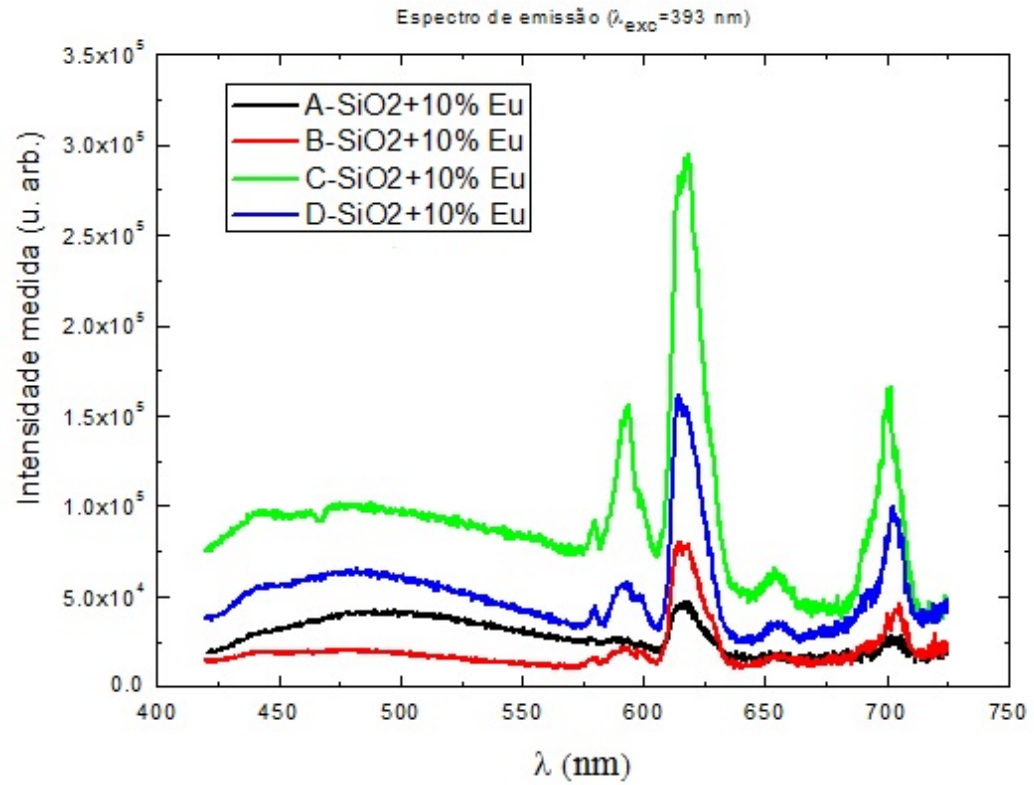

Figura 3.8: Espectro de luminescência das amostras A, B C e D.

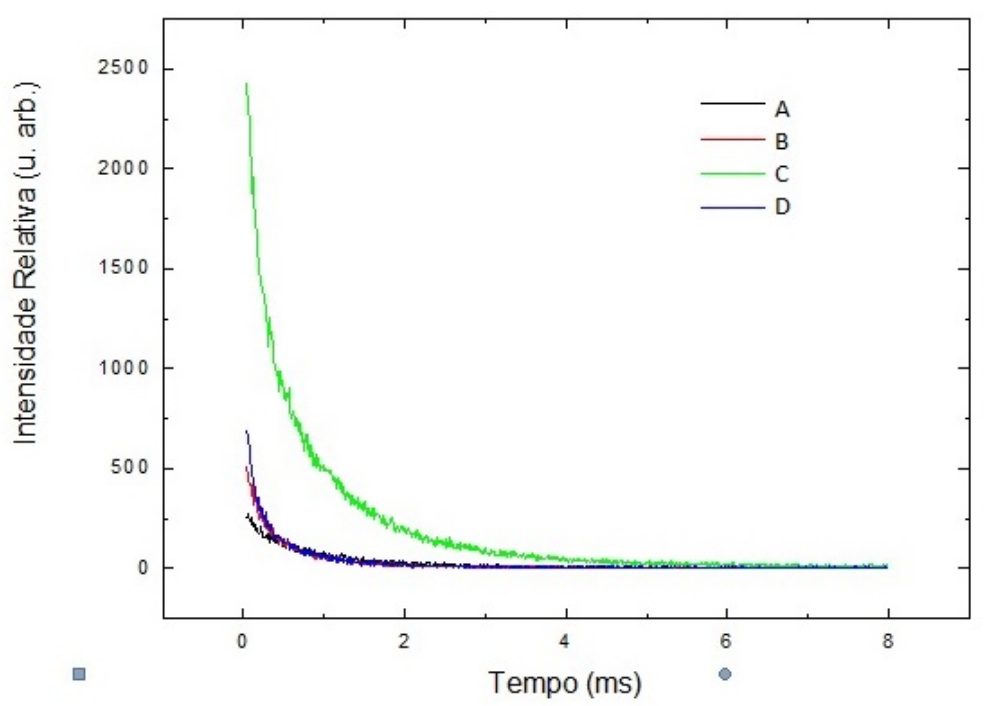

Figura 3.9: Tempo de vida das amostras A, B C e D. 
Tabela 3.7: Tempo de vida das amostras em ms.

\begin{tabular}{cc}
\hline Amostras & Tempo de vida (ms) \\
\hline A & 0,87 \\
\hline B & 0,54 \\
\hline C & 0,87 \\
\hline D & 0,47 \\
\hline
\end{tabular}

A amostra $\mathrm{C}$ foi a que apresentou melhor resultado de luminescência pois o efeito de repouso e sobrenadante contribuíram para maior incorporação do material na matriz da sílica. 
Para as amostras com tratamento até $900^{\circ} \mathrm{C}$, as condições de medida utilizadas foram:

Tabela 3.8: Parâmetros utilizados.

\begin{tabular}{ccc}
\hline Amostras & Excitação & Emissão \\
\hline $\mathrm{A}$ & $\lambda_{e m}=617 \mathrm{~nm}$ & $\lambda_{e x c}=392 \mathrm{~nm}$ \\
\hline $\mathrm{B}$ & $\lambda_{e m}=617 \mathrm{~nm}$ & $\lambda_{e x c}=392 \mathrm{~nm}$ \\
\hline $\mathrm{C}$ & $\lambda_{e m}=617 \mathrm{~nm}$ & $\lambda_{e x c}=392 \mathrm{~nm}$ \\
\hline $\mathrm{D}$ & $\lambda_{e m}=617 \mathrm{~nm}$ & $\lambda_{e x c}=392 \mathrm{~nm}$ \\
\hline
\end{tabular}


Resultados de luminescência até $900^{\circ} \mathrm{C}$ :

- Resultados de luminescência das amostras A, B, C e D:

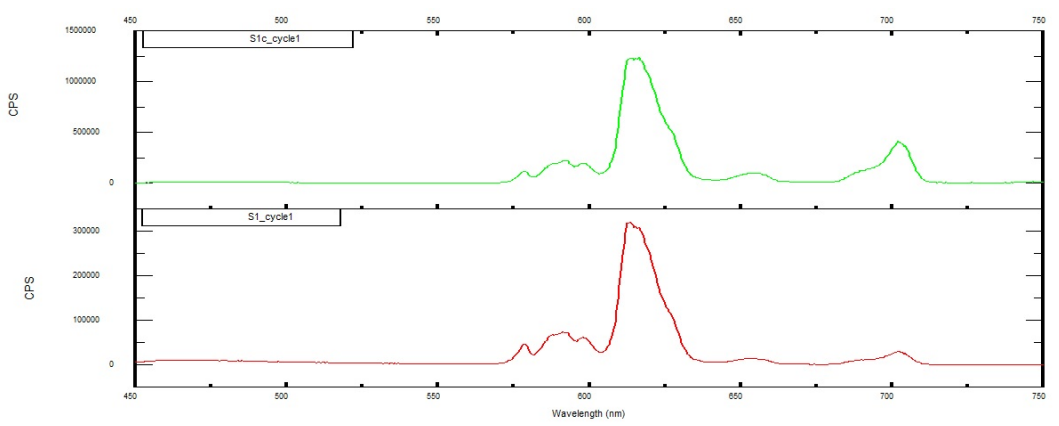

Figura 3.10: Espectro de luminescência da amostra A.

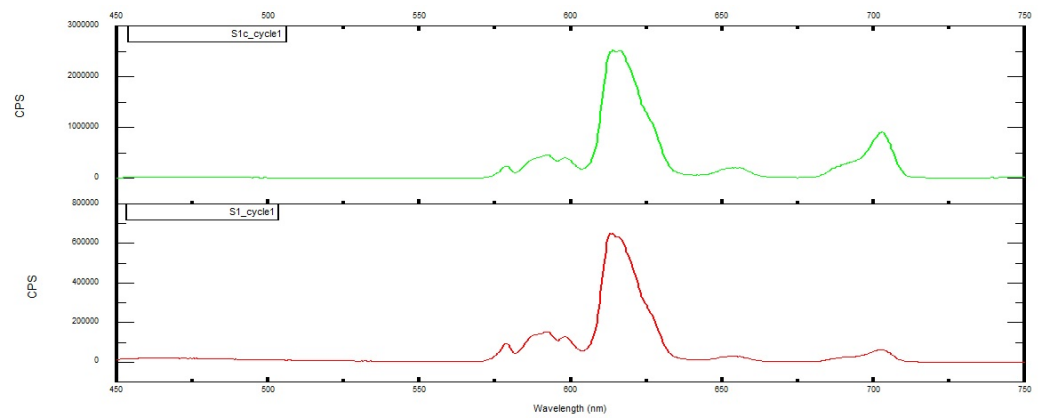

Figura 3.11: Espectro de luminescência da amostra B.

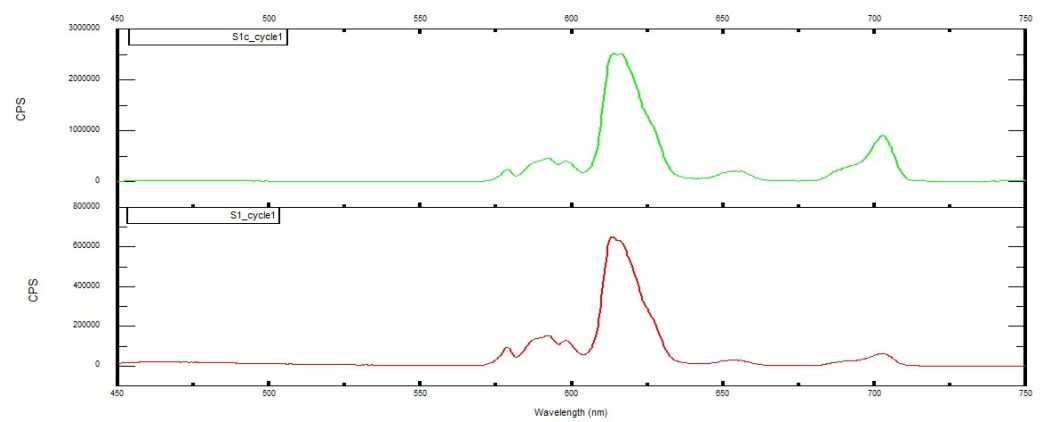

Figura 3.12: Espectro de luminescência das amostras C. 


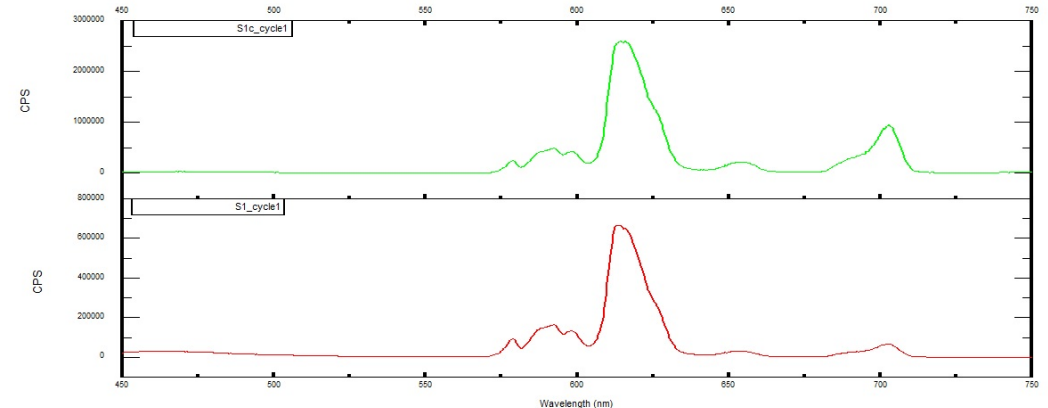

Figura 3.13: Espectro de luminescência das amostras D.

Tabela 3.9: Tempo de vida das amostras em ms.

\begin{tabular}{cc}
\hline Amostras & Tempo de vida (ms) \\
\hline A & 5,00 \\
\hline B & 6,00 \\
\hline C & 5,00 \\
\hline D & 5,00 \\
\hline
\end{tabular}

As amostras que sofreram tratamento térmico até $900^{\circ} \mathrm{C}$ apresentaram maior intensidade de luminescência. 


\subsubsection{RBS}

Seguem resultados de simulação de RBS, foi utilizada uma amostra de TiAlTa para calibrar a energia, determinar a composição das amostras bem como a relação $\mathrm{Si} / \mathrm{Eu}$ em átomos por $\mathrm{cm}^{2}$. Em todas os resultados, a região do elemento oxigênio não é bem ajustada devido a efeitos de espalhamento que não são possíveis de serem simulados através do software Rump. As medidas de RBS foram realizadas no LAMFI-USP (Laboratório de Análise de Materiais por Feixes Iônicos).

Tabela 3.10: Resultados simulados de RBS para as amostras contendo európio.

\begin{tabular}{ccccc}
\hline Amostras & $\mathbf{E u ~}(\mathbf{Z}=\mathbf{1 5 1 , 9 6})$ & $\mathbf{S i}(\mathbf{Z}=\mathbf{2 8 , 0 9})$ & $\mathbf{O}(\mathbf{Z}=\mathbf{1 6})$ & Soma \\
\hline 388J: A & 6,3 & 90 & 230 & 326,3 \\
\hline 389J: B & 8,15 & 105 & 240 & 353,15 \\
\hline 390J: C & 12 & 100 & 270 & 382 \\
\hline 391J: D & 6 & 130 & 225 & 361 \\
\hline
\end{tabular}

A partir dos resultados obtidos através da simulação de cada elemento, é possível obter a concentração relativa de átomos fazendo a divisão de cada elemento pelo resultado da soma total 3.10 .

Tabela 3.11: Concentrações relativas de átomos por amostra.

\begin{tabular}{cccc}
\hline Amostras & Eu $(\mathbf{Z}=\mathbf{1 5 1 , 9 6})$ & Si $(\mathbf{Z}=\mathbf{2 8 , 0 9})$ & $\mathbf{O}(\mathbf{Z}=\mathbf{1 6})$ \\
\hline 388J: A & 0,019 & 0,275 & 0,704 \\
\hline 389J: B & 0,023 & 0,297 & 0,679 \\
\hline 390J: C & 0,031 & 0,261 & 0,706 \\
\hline 391J: D & 0,016 & 0,360 & 0,623 \\
\hline
\end{tabular}

Multiplicando os resultados obtidos na tabela 3.11, multiplicados pelo numero atômico de cada elemento, e possível obter o resultado em termos de massa. 
Tabela 3.12: Concentrações dadas em massa por amostra.

\begin{tabular}{ccccc}
\hline Amostras & $\mathbf{E u ~}(\mathbf{Z}=\mathbf{1 5 1 , 9 6})$ & Si $(\mathbf{Z}=\mathbf{2 8 , 0 9})$ & $\mathbf{O}(\mathbf{Z}=\mathbf{1 6})$ & Soma \\
\hline 388J: A & 2,933 & 7,747 & 11,277 & 21,960 \\
\hline 389J: B & 3,506 & 8,352 & 10,873 & 22,732 \\
\hline 390J: C & 4,773 & 7,353 & 11,308 & 23,435 \\
\hline 391J: D & 2,525 & 10,115 & 9,972 & 22,613 \\
\hline
\end{tabular}

Dividindo o valor da massa de cada elemento pela soma total da amostra, conforme resultados da tabela 3.12 , obtém-se os resultados de quanto európio esta presente na matriz de sílica. Os resultados abaixo apresentam a relação em massa e em áomos.

Tabela 3.13: Concentrações relativas de európio na matriz de sílica.

\begin{tabular}{cccc}
\hline Amostras & Eu/SiO2 (em massa) & Eu/Si (em massa) & Eu/Si (em átomos) \\
\hline 388J: A & 0,097 & 0,378 & 0,070 \\
\hline 389J: B & 0,116 & 0,420 & 0,077 \\
\hline 390J: C & 0,160 & 0,650 & 0,120 \\
\hline 391J: D & 0,084 & 0,250 & 0,046 \\
\hline
\end{tabular}

A partir dos resultados, e possível concluir que a amostra $\mathrm{C}$ apresenta maior quantidade de európio na matriz de sílica. 
- $\mathrm{A}$

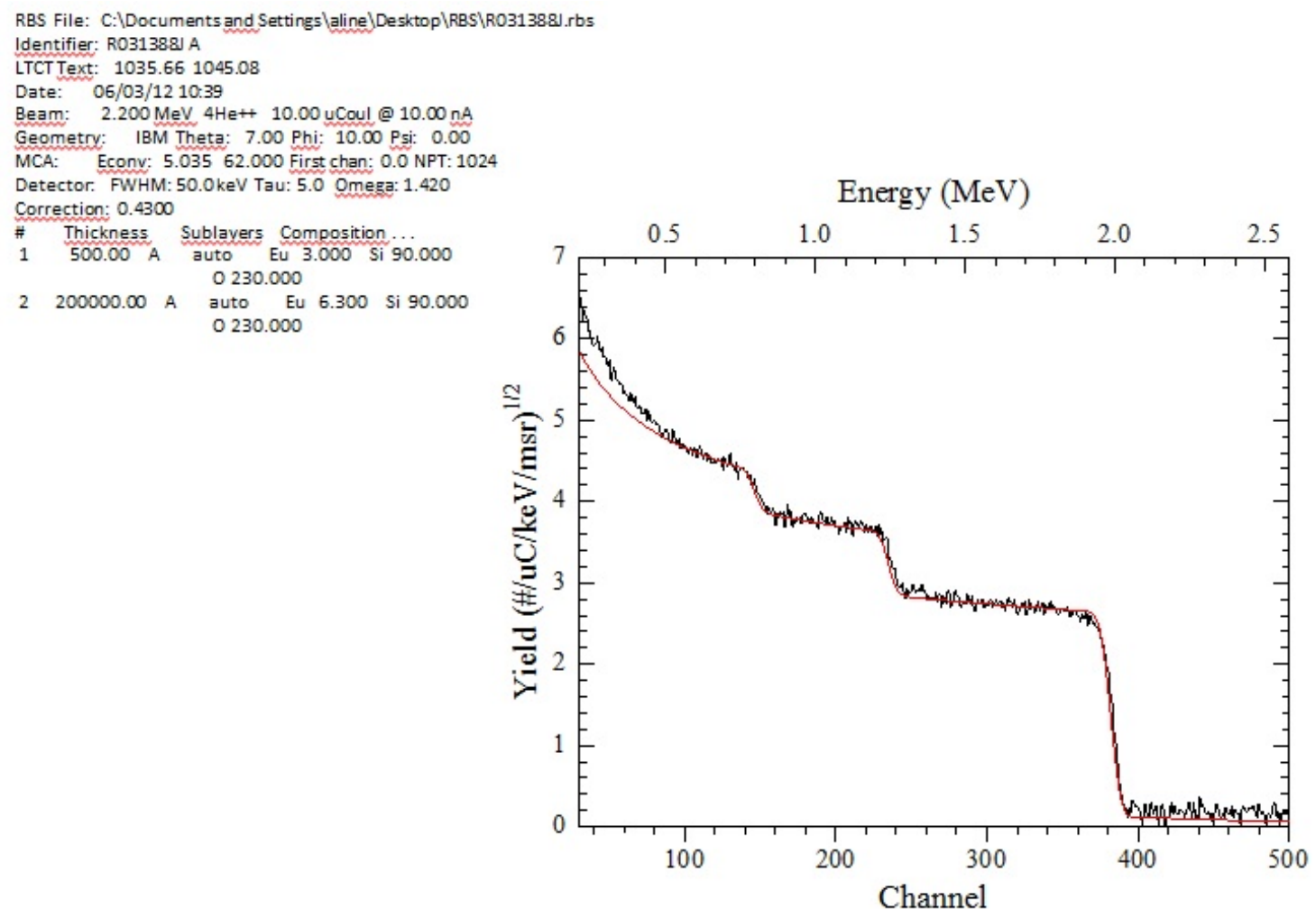

Figura 3.14: Simulação do da composição da amostra A. 
- $\mathrm{B}$

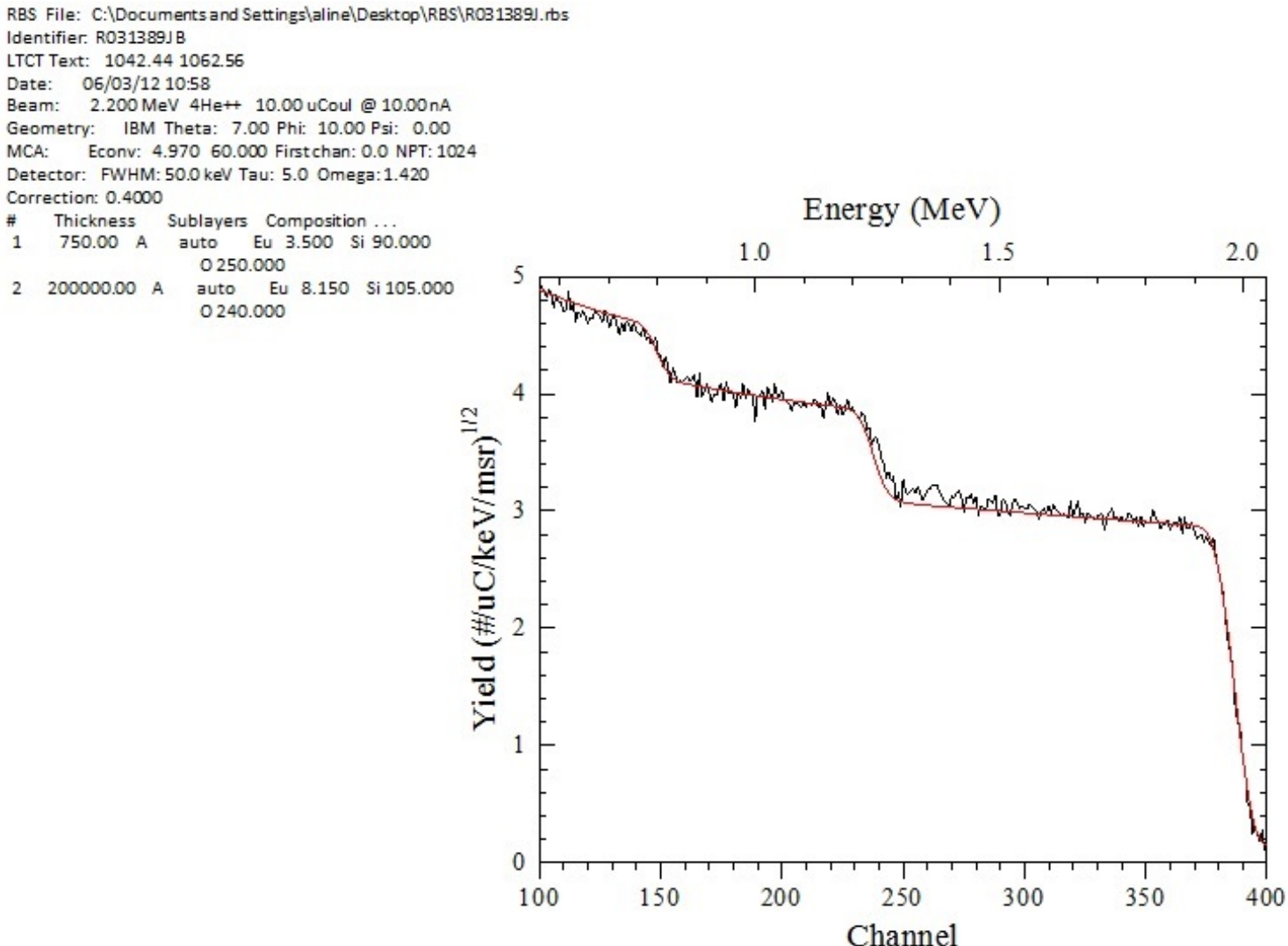

Figura 3.15: Simulação do da composição da amostra B. 
- $\mathrm{C}$

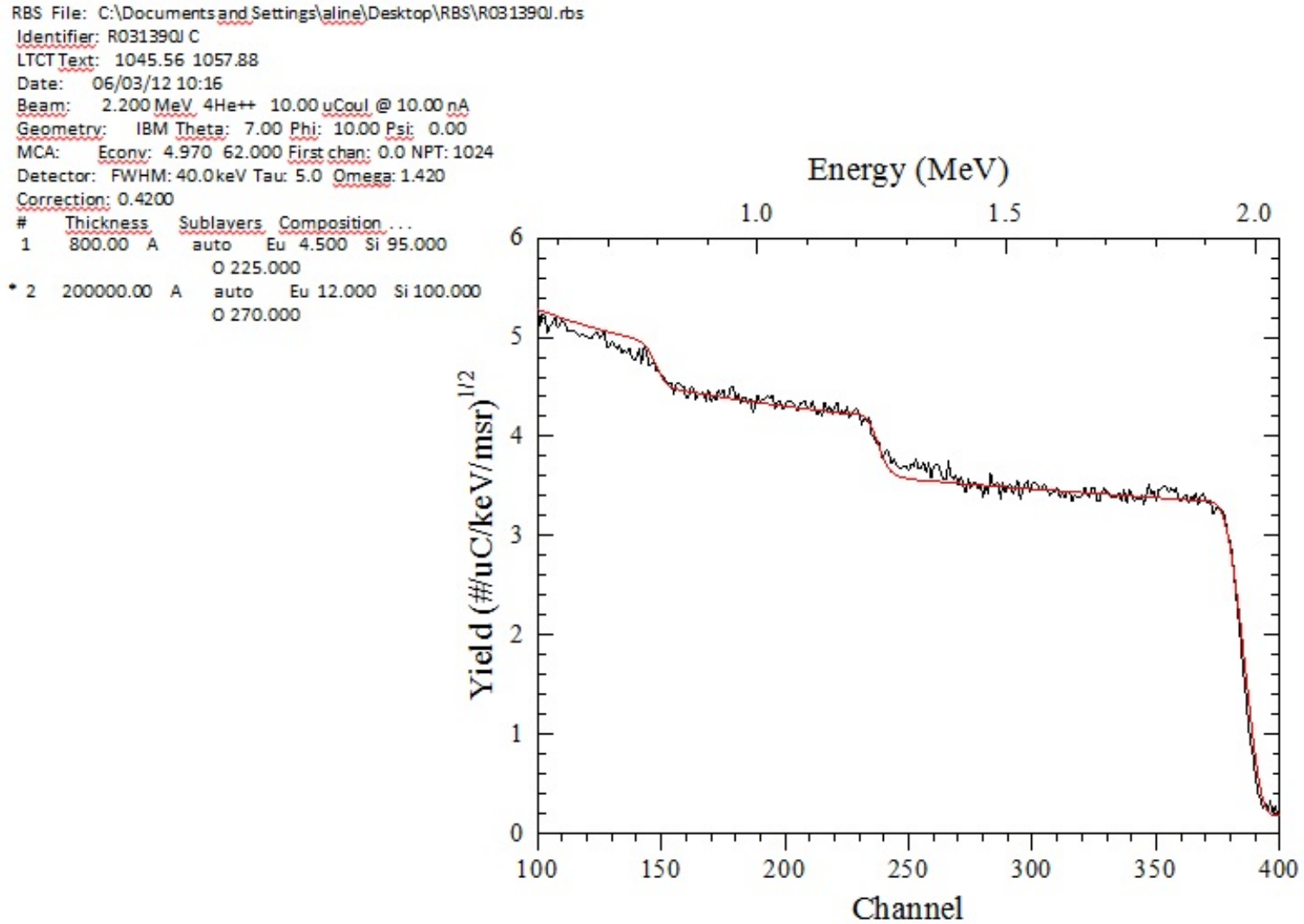

Figura 3.16: Simulação do da composição da amostra C. 
- $\mathrm{D}$

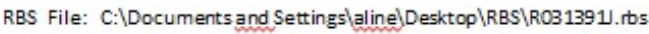

Identifier. R031391J D

LTCT Text: 1113.781121 .6

Date: 06/03/12 11:45

Beam: $\quad 2.200 \mathrm{MeV} 4 \mathrm{He}+10.00 \mathrm{uCoul} @ 10.00 \mathrm{n}$

Geometry: IBM Theta: 7.00 Phi: 10.00 Psi: 0.00

MCA: Econv: 4.970 65.000 Firstchan: 0.0 NPT: 1024

Detector: FWHM: $40.0 \mathrm{keV}$ Tau: 5.0 Omega: 1.420

Correction: 0.5000

\# Thickness Sublayers, Composition ...

1 . $500.00 \mathrm{~A}$ auto Eu 3.000 Si 90.000

$2200000.00 \mathrm{~A}$ auto Eu 6.000 Si 130.000

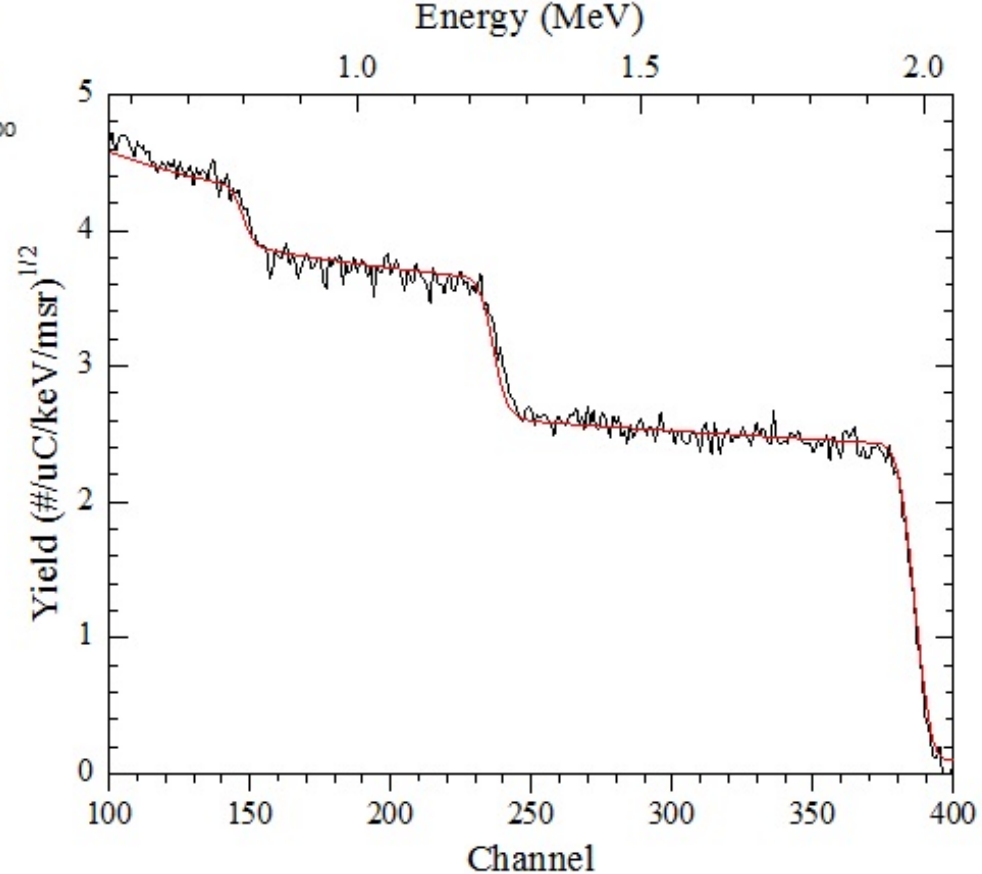

Figura 3.17: Simulação do da composição da amostra D. 


\subsubsection{XRD}

Os resultados de XRD foram obtidos utilizando as seguintes condições:

Tabela 3.14: Resultados XRD.

\begin{tabular}{cc}
\hline Voltagem & $40 \mathrm{kV}$ \\
\hline Amperagem & $30 \mathrm{~mA}$ \\
\hline $2 \theta$ & $10^{\circ}$ a $90^{\circ}$ \\
\hline Passo & $0,05^{\circ}$ \\
\hline Tempo & $10 \mathrm{~s}$ \\
\hline RPM & 15 \\
\hline
\end{tabular}


Com sobrenadante - resultados das amostras sem e com repouso Amostra B

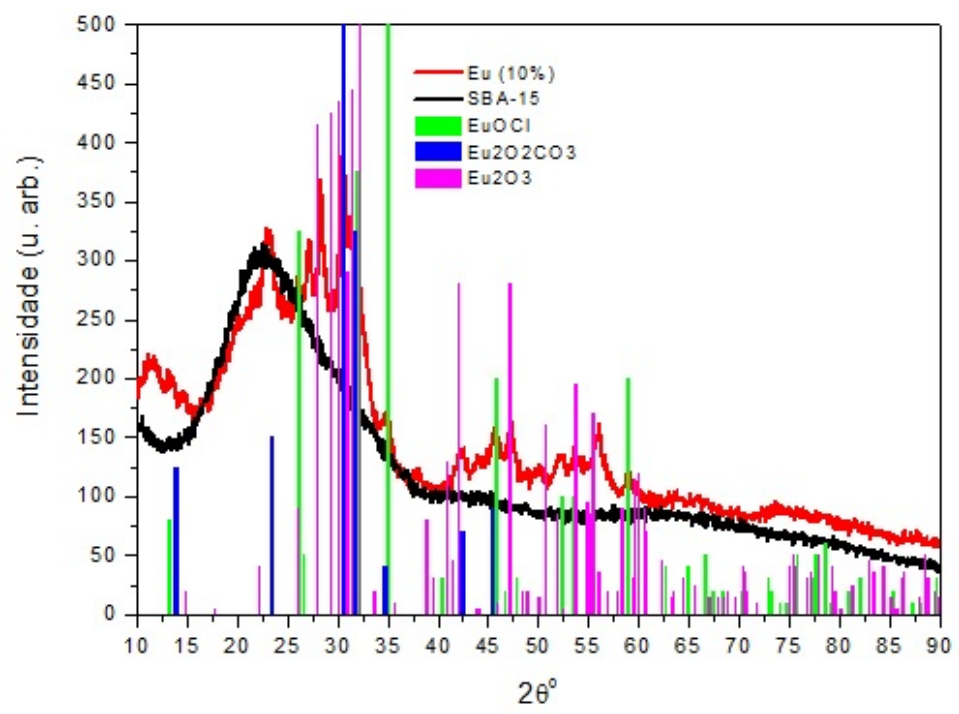

Figura 3.18: Resultado de XRD da amostra B.

Amostra C

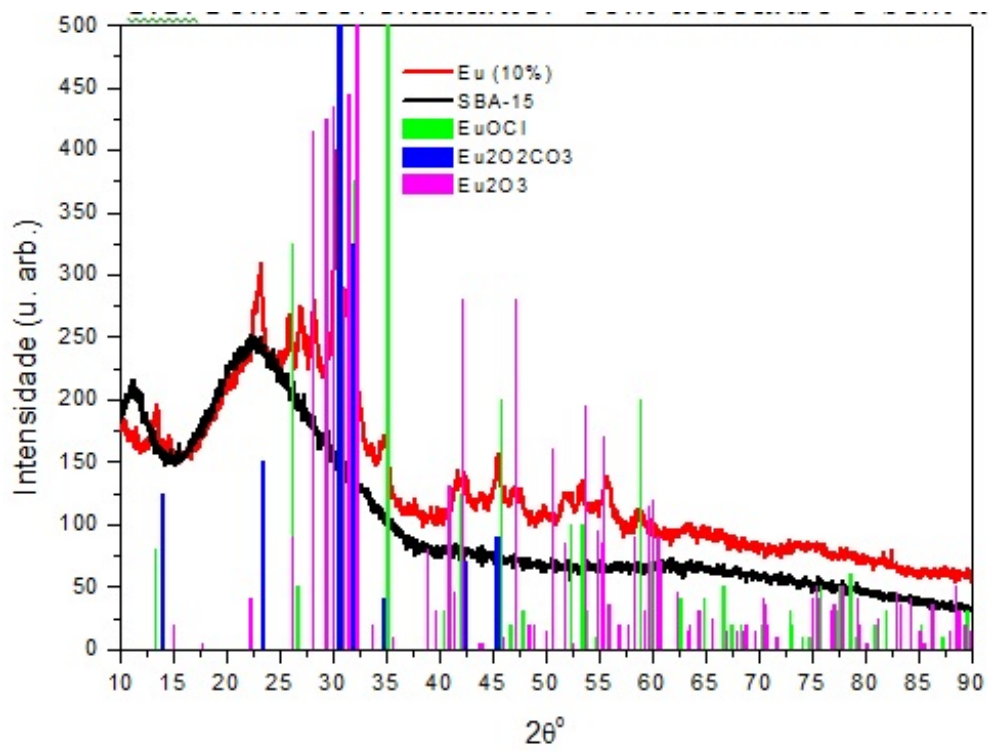

Figura 3.19: Resultado de XRD da amostra C. 
Sem sobrenadante - resultados das amostras sem e com repouso Amostra A

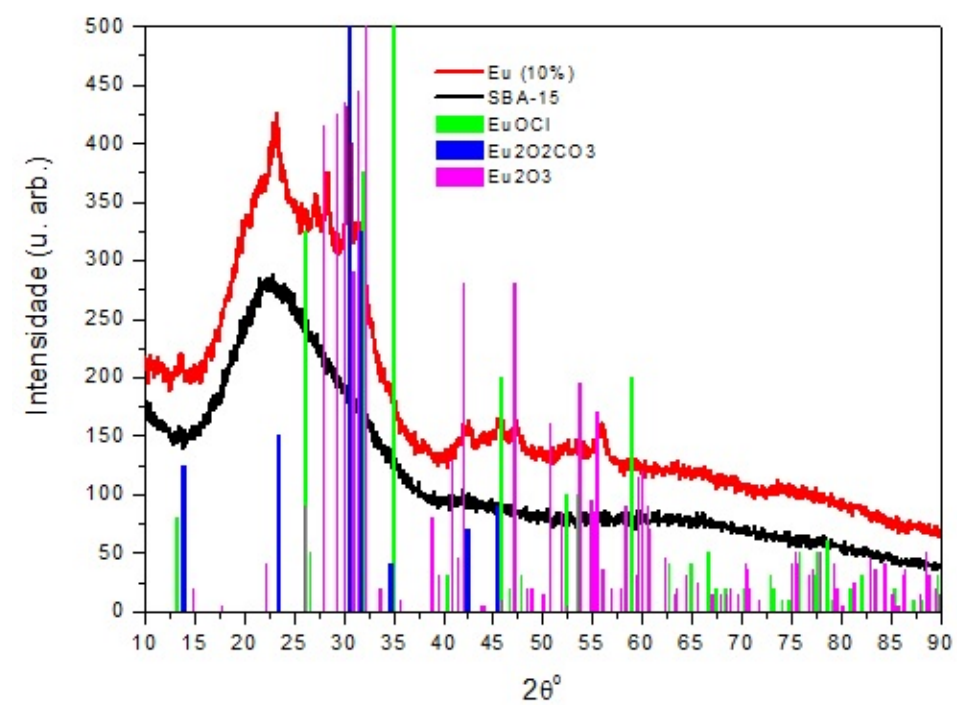

Figura 3.20: Resultado de XRD da amostra A.

Amostra D

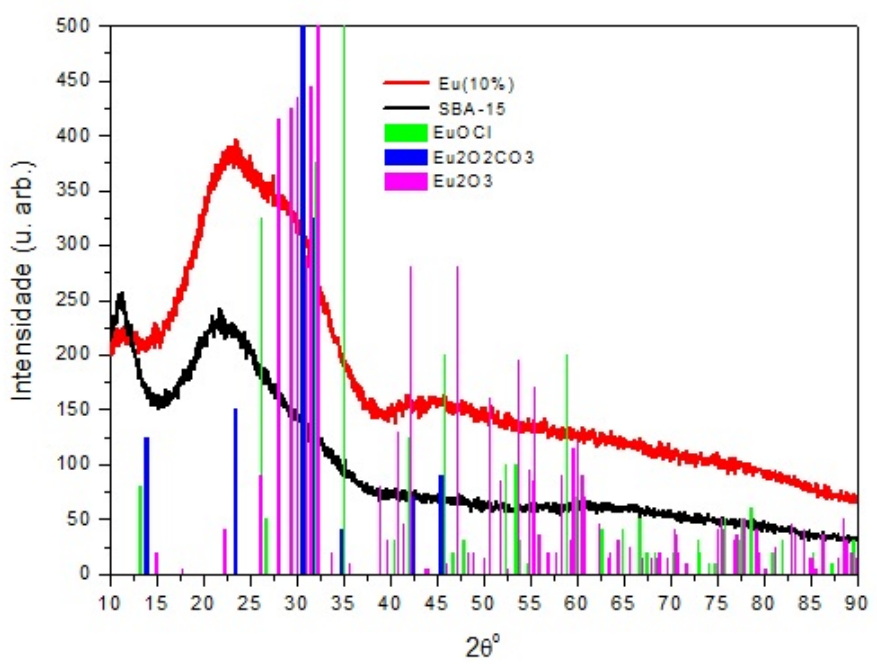

Figura 3.21: Resultado de XRD da amostra D. 
Comparando todos os resultados

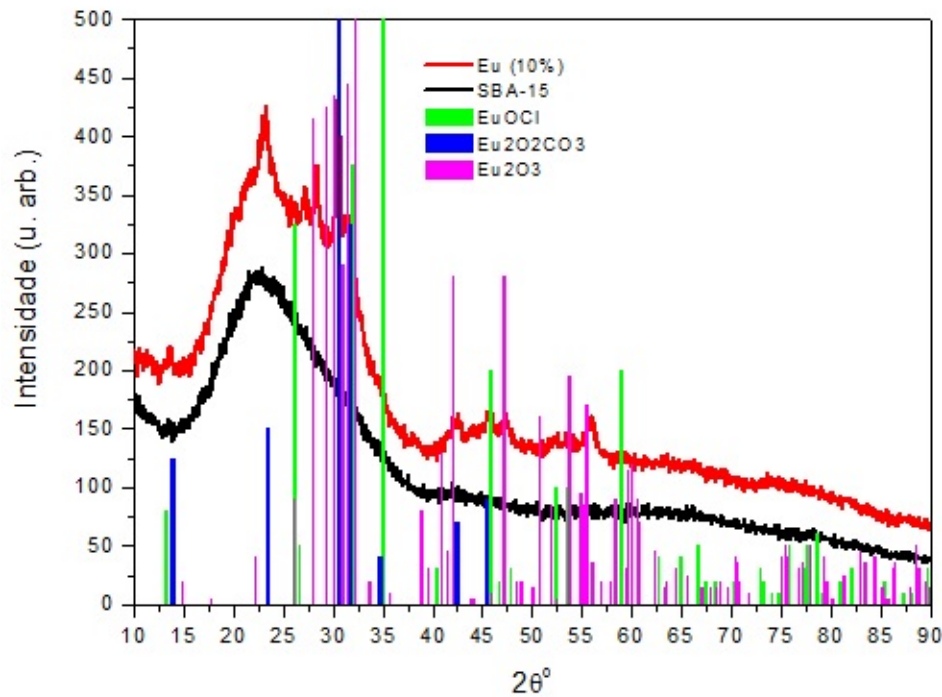

Figura 3.22: Resultado de XRD das amostras até $650^{\circ} \mathrm{C}$.

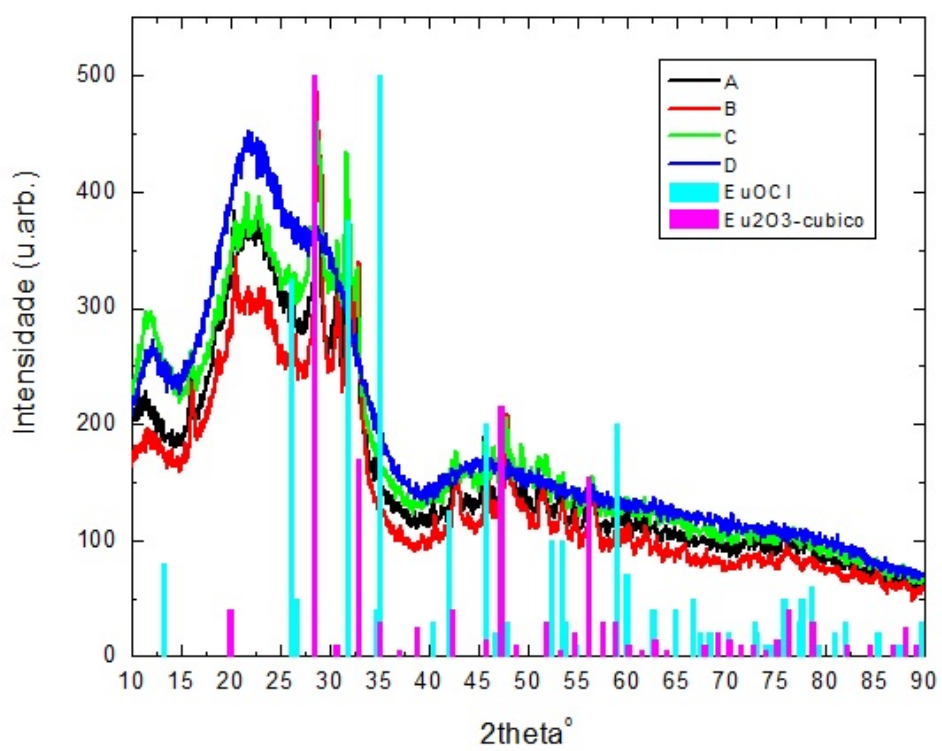

Figura 3.23: Resultado de XRD das amostras até $900^{\circ} \mathrm{C}$. 
- A e D: apresentam uma banda mais intensa relacionada à sílica, devido à provável remoção do composto luminescente do sobrenadante. O descanso influencia a incorporação do precursor de Eu na matriz da sílica. Tais resultados são consistentes com os dados de NAI, pois A e D são as amostras que apresentam a maior área superficial.

- C: possui maior intensidade dos picos de difração associados a compostos de európio com $\mathrm{O}, \mathrm{C}$ e $\mathrm{Cl}$, o que concorda com os resultados de RBS.

- O aquecimento das amostras até $900^{\circ} \mathrm{C}$ foi efetuado para a eliminação das fases com carbono e formação do óxido, como mostrado na 3.23 . 


\subsubsection{NAI}

\subsubsection{Amostras contendo Európio}

Seguem resultados de NAI e PSD para as amostras contendo material luminescente.

Tabela 3.15: NAI das amostras contendo Eu.

\begin{tabular}{ccccc}
\hline Amostras & $\mathrm{BET}\left(\mathrm{m}^{2} / \mathrm{g}\right)$ & $\mathrm{BJH}\left(\mathrm{cm}^{3} / \mathrm{g}\right)$ & Volume microporo $\left(\mathrm{cm}^{3} / \mathrm{g}\right)$ & PSD $(\mathrm{nm})$ \\
\hline $\mathrm{A}$ & 476 & 1,5 & - & 10,5 \\
\hline $\mathrm{B}$ & 380 & 1,1 & - & 10,3 \\
\hline $\mathrm{C}$ & 338 & 0,8 & 0,15 & 9,9 \\
\hline $\mathrm{D}$ & 654 & 1,3 & 0,83 & 9,4 a 10,2 \\
\hline
\end{tabular}


Com sobrenadante - resultados das amostras com e sem repouso (B e C).

Resultados da amostra B

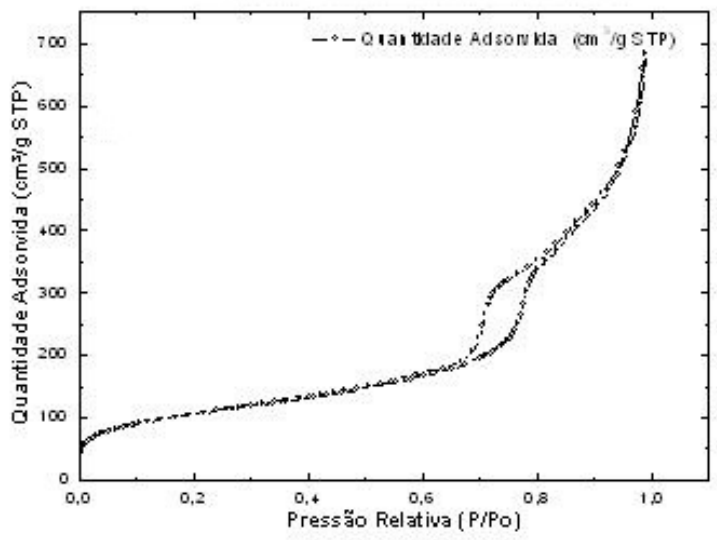

Figura 3.24: Isoterma da amostra B (Eu com sobrenadante e sem repouso).

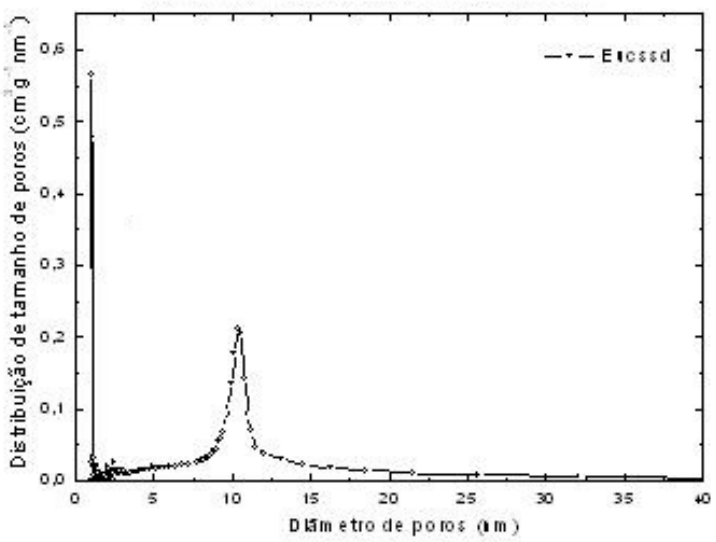

Figura 3.25: Distribuição do tamanho de poros da amostra B (Eu com sobrenadante e sem repouso). 
Resultados da amostra C

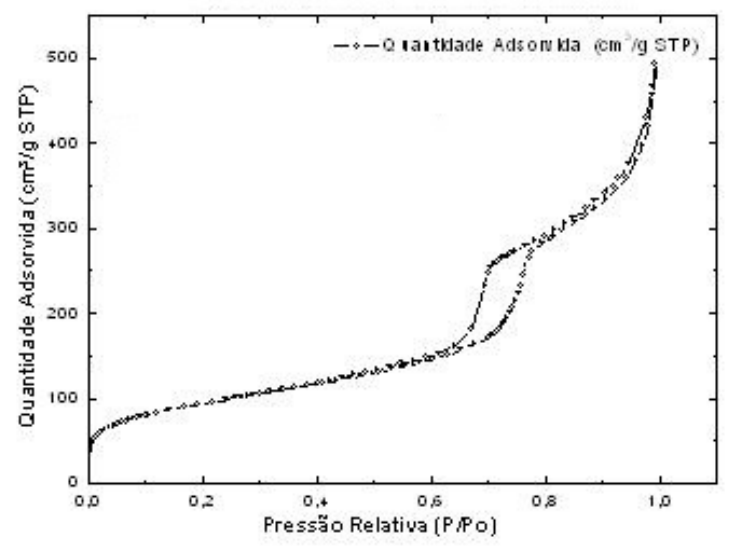

Figura 3.26: Isoterma da amostra C (Eu com sobrenadante e com repouso).

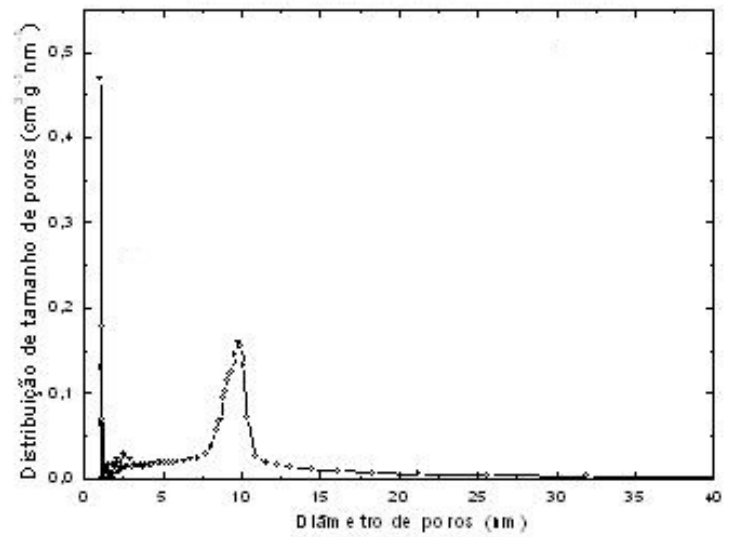

Figura 3.27: Distribuição do tamanho de poros da amostra C (Eu com sobrenadante e com repouso). 
Comparando resultados:

- C e B: apresentam menor área superficial e de volume de poros. É um indicativo de que pode haver maior porcentagem de európio incorporado à matriz de sílica.

Os resultados apontam que uma síntese com sobrenadante e com repouso (C), contribui para uma melhor incorporação de precursores de Eu na matriz. 
Sem sobrenadante - resultados das amostras com e sem repouso (A e D) Resultados da amostra A

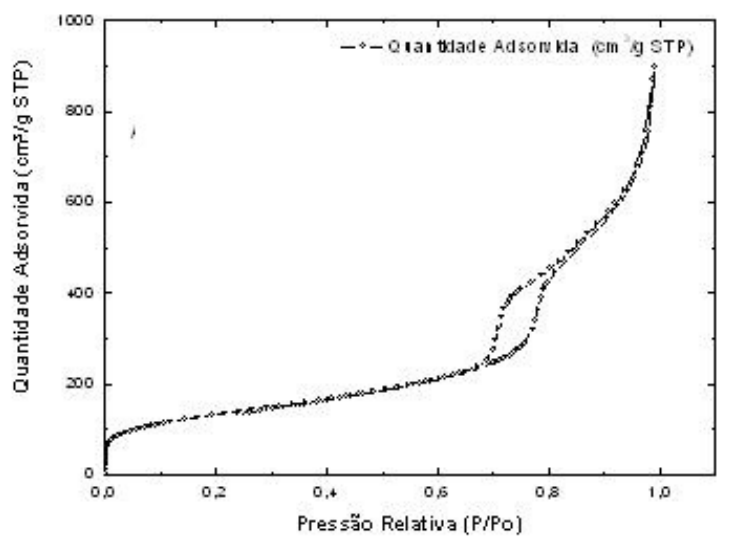

Figura 3.28: Isoterma da amostra A (Eu sem sobrenadante e sem repouso).

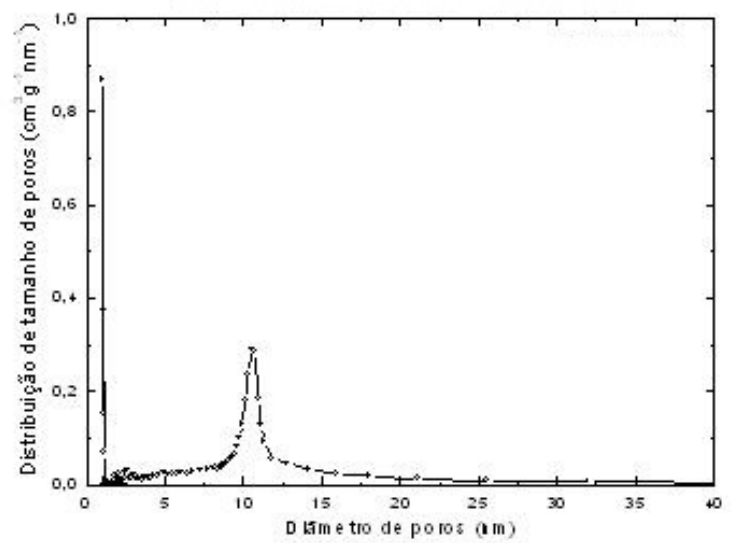

Figura 3.29: Distribuição do tamanho de poros da amostra A (Eu sem sobrenadante e sem repouso). 
Resultados da amostra D

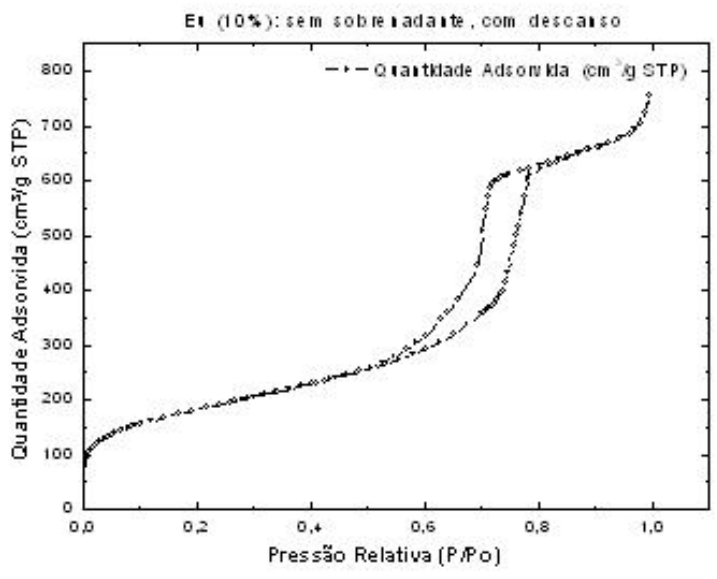

Figura 3.30: Isoterma da amostra D (Eu sem sobrenadante e com repouso).

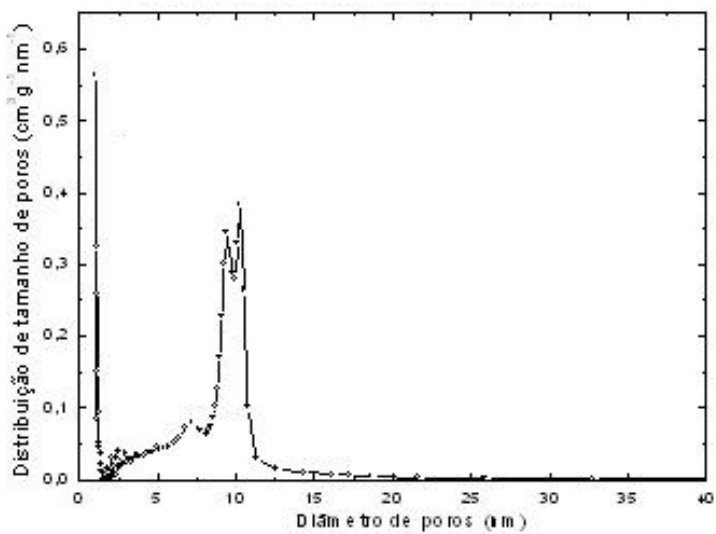

Figura 3.31: Distribuição do tamanho de poros da amostra D (Eu sem sobrenadante e com repouso). 
Comparando as amostras:

- A e D (ss): apresentam maior volume de poros, comparadas àquelas com sobrenadante. Uma hipótese deste resultado é a remoção de resíduos nos poros e na superfície do material.

Ao comparar as amostras que passaram pelo processo de repouso, amostras $\mathrm{C}$ e D, apresentam um alargamento, ou mesmo uma distribuição bimodal de tamanhos de poros (PSD), o que pode estar associado à incorporação dos compostos de európio em partes distintas da estrutura. 


\subsubsection{Amostras de SBA-15}

Seguem resultados de NAI e PSD para as amostras de SBA-15 pura.

Tabela 3.16: NAI das amostras de SBA-15.

\begin{tabular}{ccccc}
\hline Amostras & $\mathrm{BET}\left(\mathrm{m}^{2} / \mathrm{g}\right)$ & $\mathrm{BJH}\left(\mathrm{cm}^{3} / \mathrm{g}\right)$ & Volume microporo $\left(\mathrm{cm}^{3} / \mathrm{g}\right)$ & PSD $(\mathrm{nm})$ \\
\hline $\mathrm{E}$ & 442 & 0,84 & 0,56 & 9,7 \\
\hline $\mathrm{F}$ & 715 & 1,2 & 0,81 & 9,4 \\
\hline $\mathrm{G}$ & 667 & 1,5 & 0,03 & 10,3 \\
\hline $\mathrm{H}$ & 851 & 1,5 & 0,99 & 10,6 \\
\hline
\end{tabular}


Com sobrenadante - resultados das amostras com e sem repouso (E e G).

Resultados da amostra E

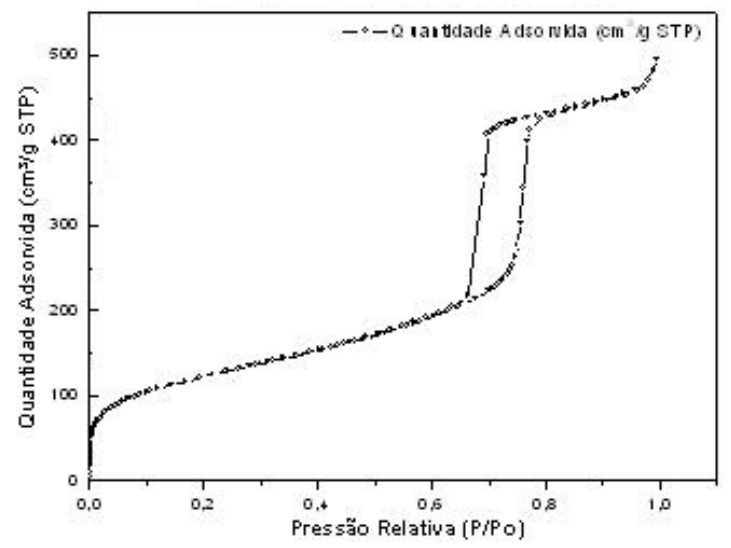

Figura 3.32: Isoterma da amostra E (SBA-15 com sobrenadante e sem repouso).

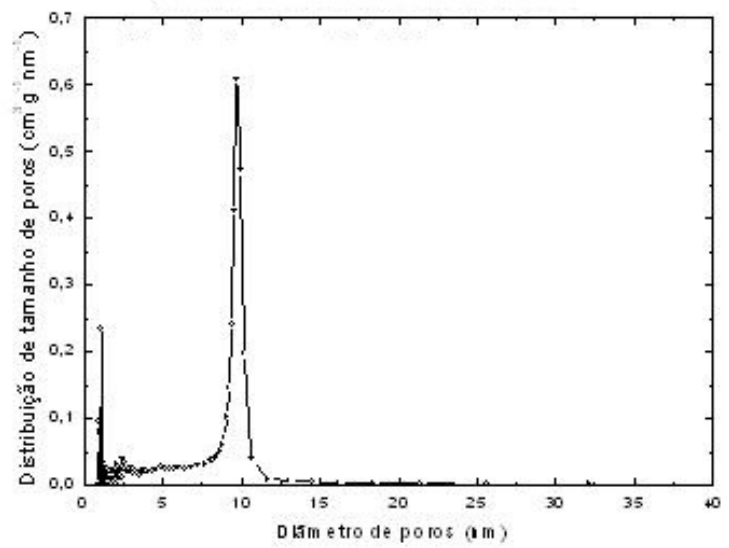

Figura 3.33: Distribuição do tamanho de poros da amostra E (SBA-15 com sobrenadante e sem repouso). 
Resultados da amostra $\mathrm{G}$

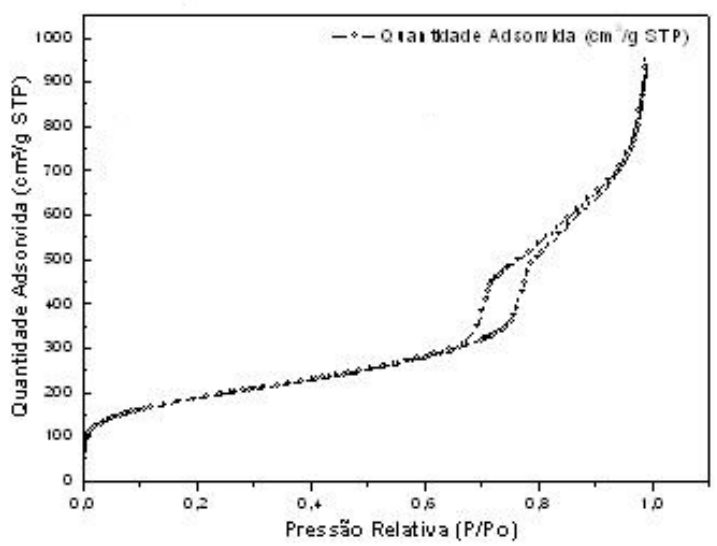

Figura 3.34: Isoterma da amostra G (SBA-15 com sobrenadante e com repouso).

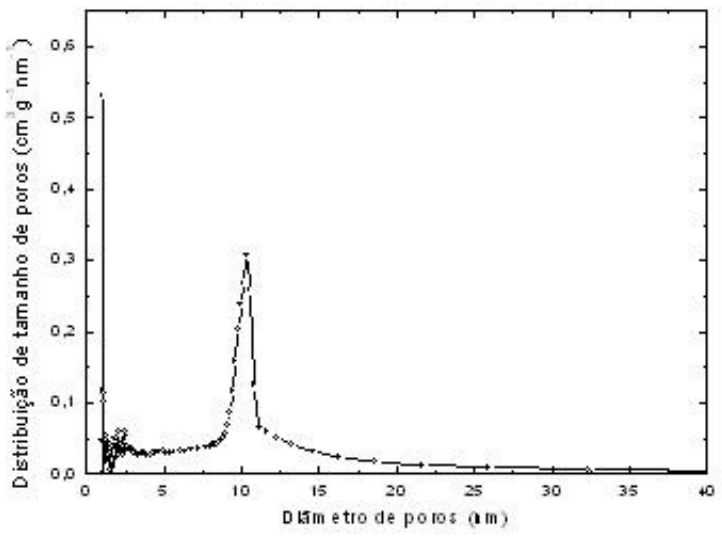

Figura 3.35: Distribuição do tamanho de poros da amostra G (SBA-15 com sobrenadante e com repouso). 
Sem sobrenadante - resultados das amostras com e sem repouso (F e H). Resultados da amostra F

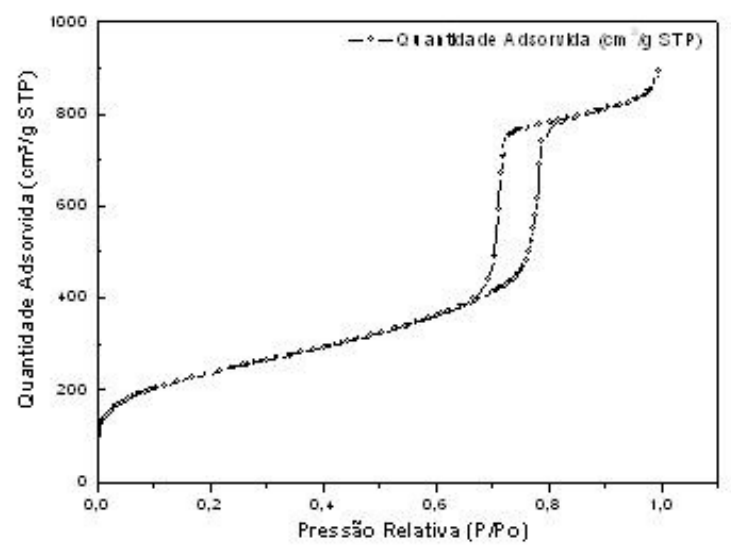

Figura 3.36: Isoterma da amostra F (SBA-15 sem sobrenadante e sem repouso).

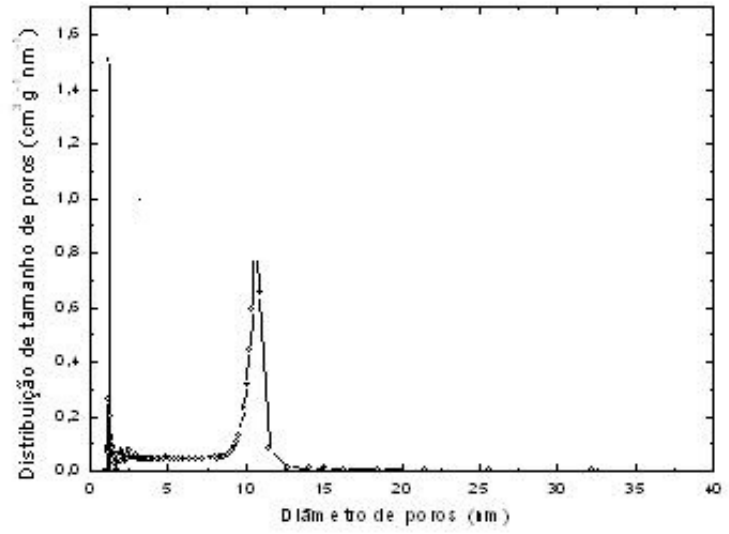

Figura 3.37: Distribuição do tamanho de poros da amostra F (SBA-15 sem sobrenadante e sem repouso). 
Resultados da amostra $\mathrm{H}$

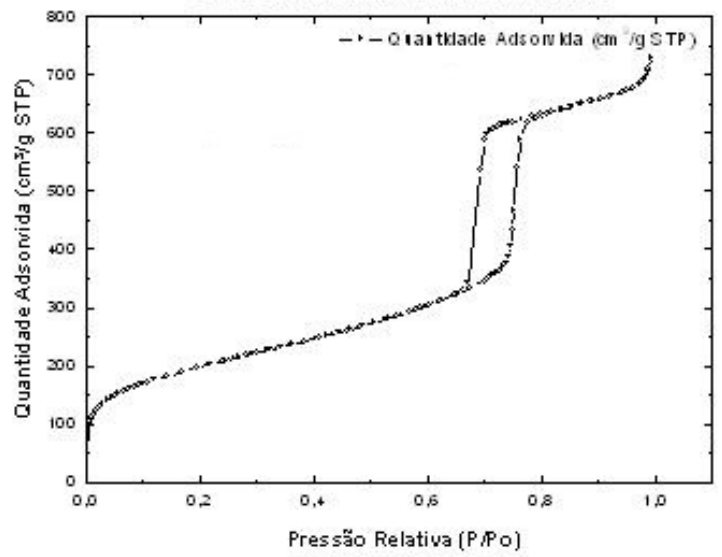

Figura 3.38: Isoterma da amostra H (SBA-15 sem sobrenadante e com repouso).

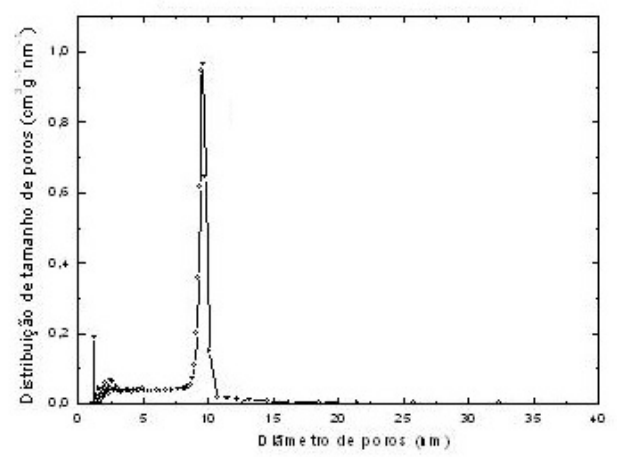

Figura 3.39: Distribuição do tamanho de poros da amostra H (SBA-15 sem sobrenadante e com repouso).

- H e F: Tal qual o observado para as síntese com Eu, as amostras sem sobrenadante, apresentam maior área superficial, volume de poros e microporos. O sobrenadante deve provocar alterações na estrutura devido à secagem em solução ácida da própria síntese. Os resultados de XRD mostram o aparecimento de uma banda de difração a baixos ângulos $\left(10^{\circ}<2\right.$ theta $\left.<15^{\circ}\right)$ indicando a formação de um composto durante o repouso. 


\subsubsection{MEV}

Abaixo seguem os resultados de Microscopia Eletrônica de Varredura, estes resultados foram analisados de forma qualitativa, avaliando as alterações morfológicas das amostras

- A

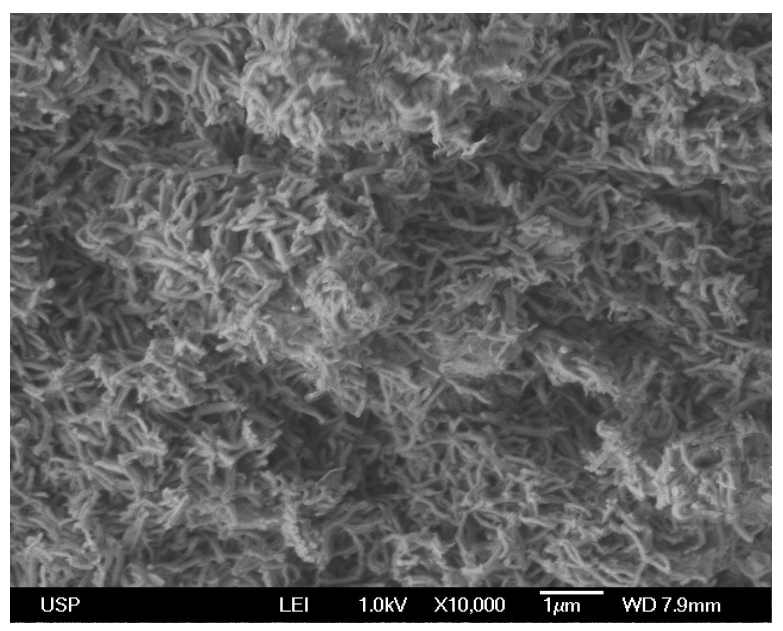

Figura 3.40: Aspecto morfológico da amostra A.

- $\mathrm{B}$

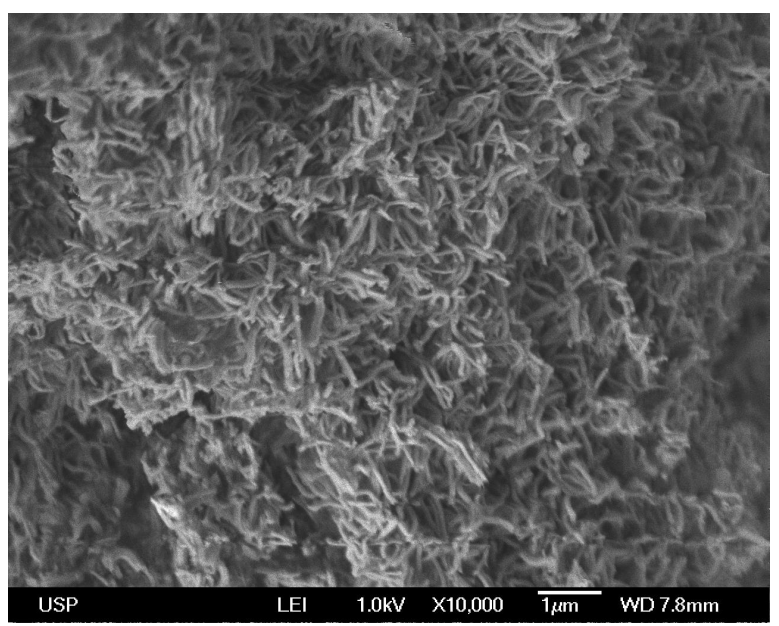

Figura 3.41: Aspecto morfológico da amostra B. 
- $\mathrm{C}$

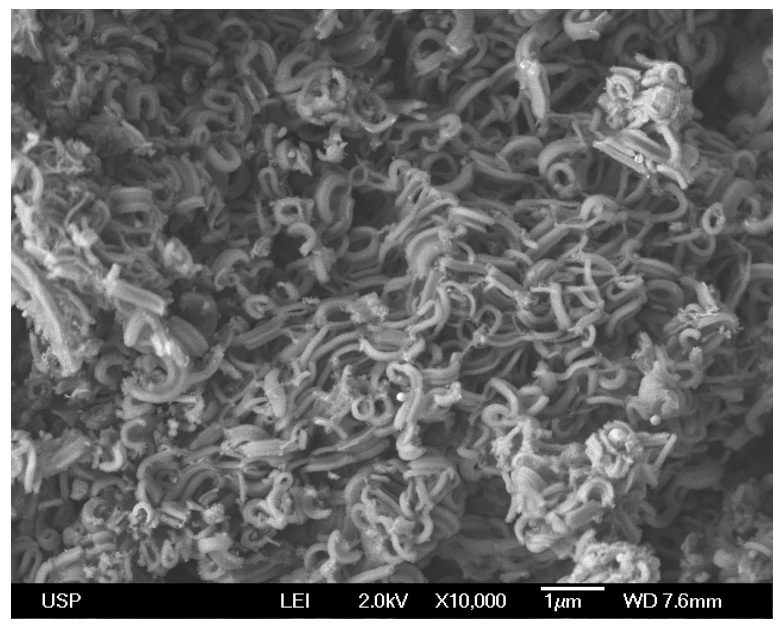

Figura 3.42: Aspecto morfológico da amostra C.

- $\mathrm{D}$

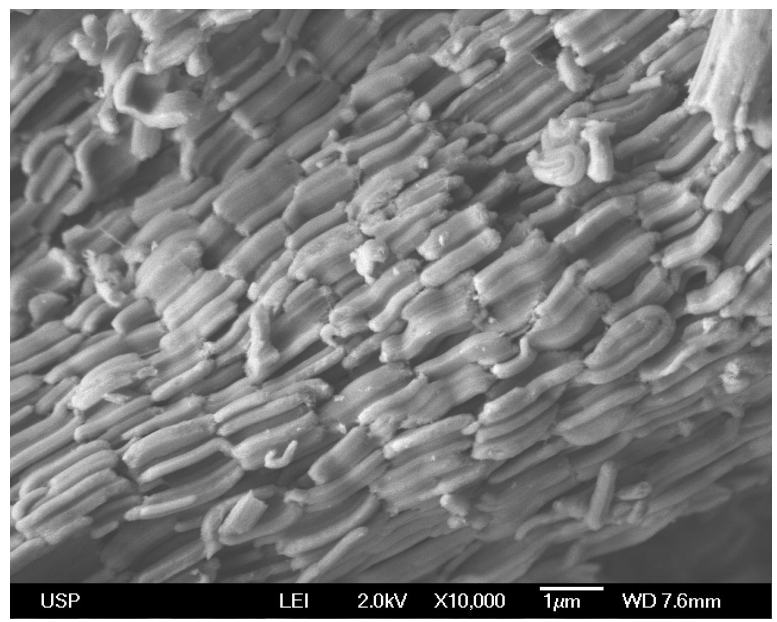

Figura 3.43: Aspecto morfológico da amostra D. 
- $\mathrm{E}$

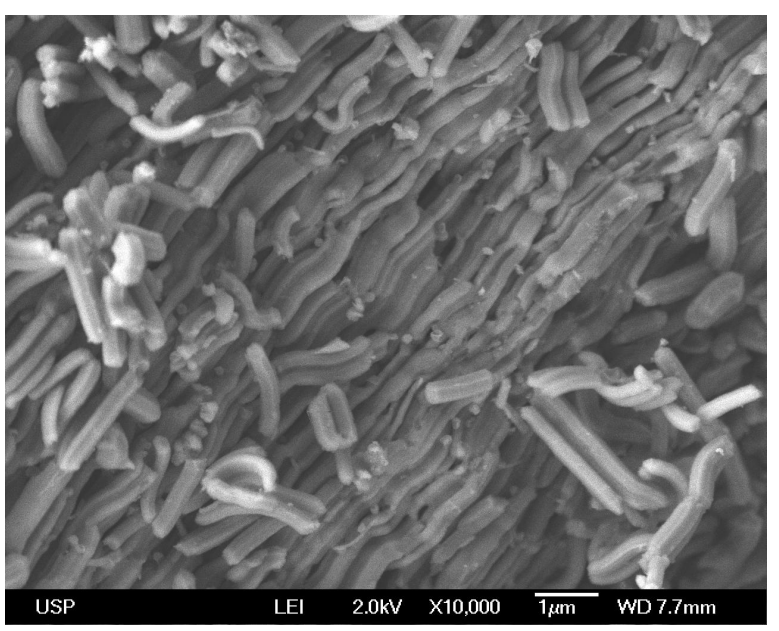

Figura 3.44: Aspecto morfológico da amostra E.

- $\mathrm{F}$

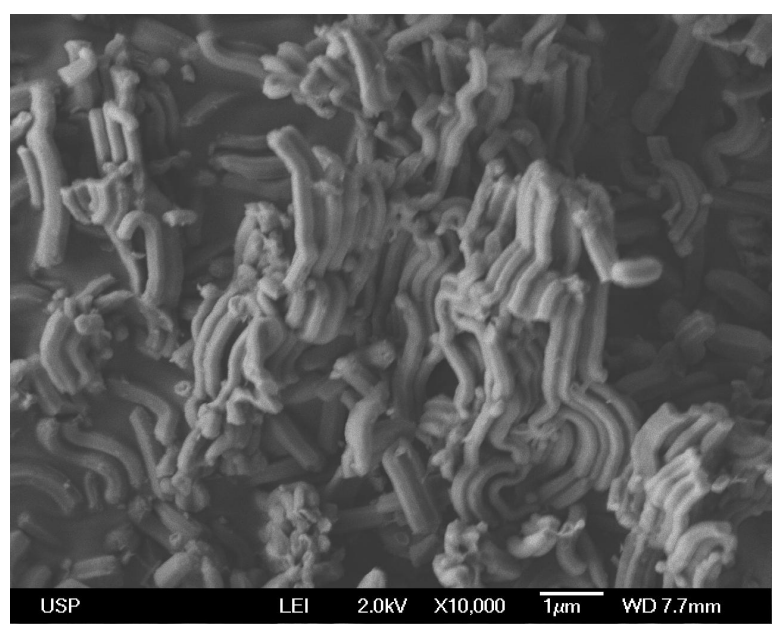

Figura 3.45: Aspecto morfológico da amostra F. 
- $\mathrm{G}$

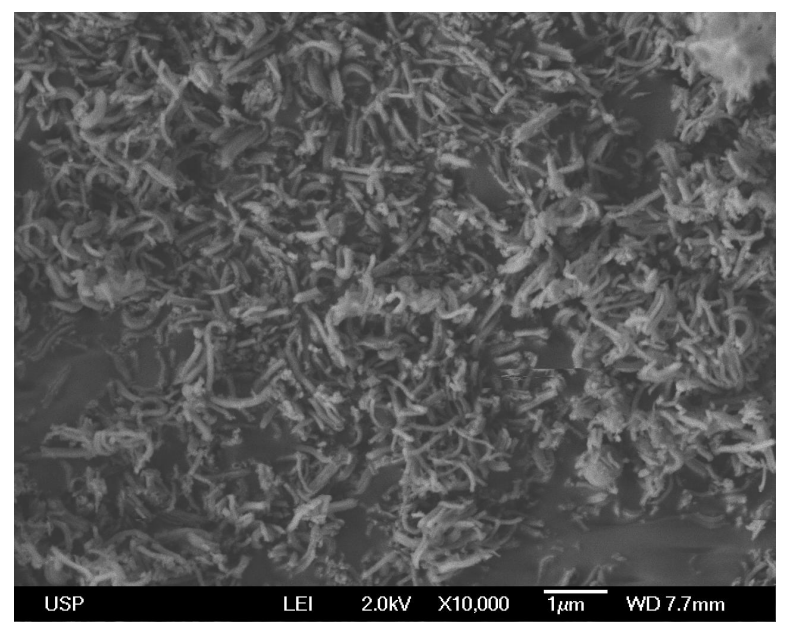

Figura 3.46: Aspecto morfológico da amostra G.

- $\mathrm{H}$

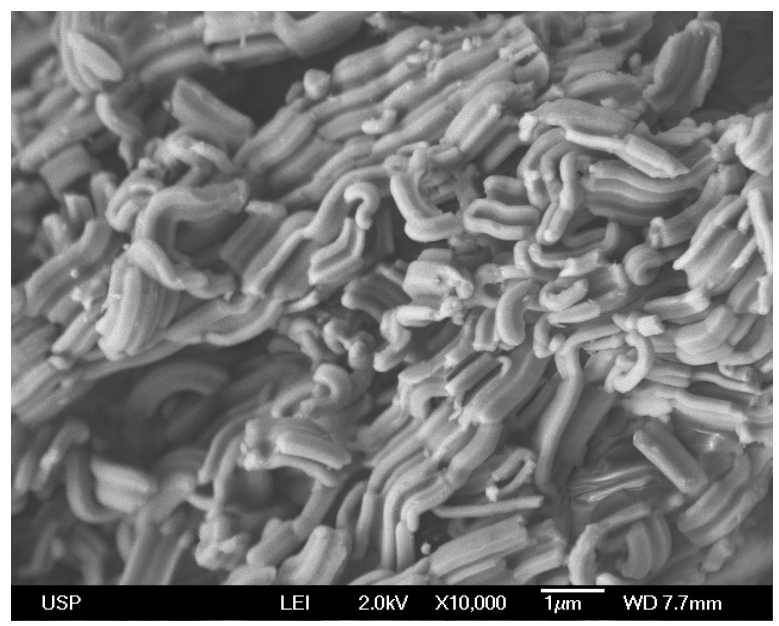

Figura 3.47: Aspecto morfológico da amostra H.

Os resultados de MEV mostram o efeito da corrosão do sobrenadante, que se intensifica com o perído de repouso, concordante com os resultados de NAI, XRD e luminescência. 


\section{Capítulo 4}

\section{Comparação dos resultados e conclusões}

\subsection{Comparação dos Resultados e conclusões}

Através da metodologia de síntese da SBA-15, precursor Eu foi incorporado à matriz da sílica através do processo de one pot synthesis. Após diversas tentativas de inclusão do precursor à matriz, o resultado que obteve maior intensidade de luminescência corresponde a inclusão do cromóforo no meio do processo de síntese. A partir da determinação da melhor forma de inclusão do precursor, outras condições foram testadas como: efeito da presença e/ou ausência de sobrenadante; ausência e/ou presença de repouso durante o processo de síntese. As amostras que foram expostas ao processo de repouso apresentaram alterações morfológicas devido a corrosão das paredes, isto ocorre pois as amostras em repouso ficaram expostas ao $\mathrm{HCl}$ por maior intervalo de tempo. O efeito do sobrenadante pode ser diretamente relacionado à intensidade de luminescência, as amostras que mantiveram o sobrenadante apresentaram maior intensidade de luminescência. A incorporação de Eu na matriz de sílica preserva a estrutura de poros ordenada. Os resultados de XRD mostraram a formação de óxidos de európio. A partir dos resultados obtidos observaram-se diferentes efeitos da presença e ausência de sobrenadante durante o período de secagem nas amostras preparadas, como por exemplo, alterações de morfologia. As amostras preparadas com sobrenadante apresentaram menor área superficial e volume de poros. Materiais que mantiveram o sobrenadante apresentaram maior conteúdo de Eu e maior intensidade de luminescência. Os resultados de NAI apresentaram alterações na morfologia da estrutura de poros, amostras com maior concentração de európio incorporada às paredes de sílica, apresentaram menor área superficial e estreitamento na curva de histerese. A simulacao de RBS feita através do software RUMP ratificou a conclusão de que a amostra $\mathrm{C}$, com presença de sobrenadante e repouso, é a amostra que apresenta maior 
quantidade de európio na matriz. As amostras simuladas foram as preparadas com concentração de $10 \%$ de európio com relação a SBA-15, os resultados demonstraram que a relação de $10 \%$ se manteve. Portanto, a metodologia aplicada atingiu seu resultado esperado.

\section{Trabalhos apresentados durante o andamento do projeto}

Encontro Anual da Sociedade Brasileira de Pesquisa em Materiais, SBPMAT 2011 - Gramado/RS.

"Luminescent hexagonal ordered mesoporous Eu:SiO2"

A. S. L. Durães ${ }^{1}$, A. V. Lourenço ${ }^{2}$, C. A. Kodaira ${ }^{3}$, H. F. Brito ${ }^{2}$, M. C. A. Fantini ${ }^{1}$

${ }^{1}$ Instituto de Física, USP. ${ }^{2}$ Instituto de Química, USP. ${ }^{3}$ Instituto de Pesquisas Energéticas e Nucleares

Hybrid Materials 2011 - Second International Conference on Multifunctional, Hybrid and Nanomaterials - Strasbourg, France.

"Luminescent hexagonal ordered mesoporous silica with Eu and Y"

A. S. L. Durães ${ }^{1}$, A. V. Lourenço ${ }^{2}$, C. A. Kodaira ${ }^{3}$, H. F. Brito ${ }^{2}$, M. C. A. Fantini ${ }^{1}$

${ }^{1}$ Instituto de Física, USP. ${ }^{2}$ Instituto de Química, USP. ${ }^{3}$ Instituto de Pesquisas Energéticas e Nucleares

Congresso de Terras Raras 2012 - João Pessoa/PB.

"Sílica mesoporosa luminescente com európio incorporado"

A. S. L. Durães ${ }^{1}$, A. V. Lourenço ${ }^{2}$, C. A. Kodaira ${ }^{3}$, H. F. Brito ${ }^{2}$, M. C. A. Fantini ${ }^{1}$

${ }^{1}$ Instituto de Física, USP. ${ }^{2}$ Instituto de Química, USP. ${ }^{3}$ Instituto de Pesquisas Energéticas e Nucleares 


\section{Referências Bibliográficas}

[1] Barrett, E. P., Joyner, L. G., And Halenda, P. P. The determination of pore volume and area distributions in porous substances. I. computations from nitrogen isotherms. Journal of the American Chemical Society 73, 1 (January 1951), 373-380.

[2] Bing YAn, L. Z., AND Li, Y. Hydrothermal synthesis, physical characterization and photoluminescence of homologous-sba-15 fabricated with $\mathrm{eu}^{3}+$. Colloids and Surfaces A: Physicochemical and Engineering Aspects 350 (2009), 147-153.

[3] C. T. Kresge, M. E. Leonowicz, W. J. R. J. C. V., And Beck, J. S. Ordered mesoporous molecular sieves synthesized by a liquid-crystaltemplate mechanism. Nature (1992), 710-712.

[4] Chao Zhang, S. G., And Xu, H. Controllable preparation and fluorescence properties of $\mathrm{y}^{3}+$ and $\mathrm{eu}^{3}+$ co-doped mesoporous silica. Journal of Solid State Chemistry 183 (2014), 1409-1415.

[5] Ciesla, U., AND SchÜth, F. Ordered mesoporous materials. Microporous and Mesoporous Materials 27 (1999), 131-149.

[6] Craievich, A. F. Small-angle X-ray scattering by nanostructured materials Handbook of Sol-Gel Science and Technology - Volume II: Materials characterization. Chapter 8. Kluwer Academic Publishers, 2005.

[7] Crepaldi, E. L., Soler-Illia, G. J., Grosso, D., Cagnol, A. B., And SANCHEZ, C. Controlled formation of highly ordered cubic and hexagonal mesoporous nanocrystalline yttria-zirconia and ceria-zirconia thin films exhibiting high thermal stability. Angewandte Chemie 42 (2003), 347-351.

[8] Cullity, B. D., And Stock, S. R. Elements of X-ray Diffraction. Prentice Hall, 2001. 
[9] E. E. S. Teotonio, G. M. Fett, H. F. B. W. M. F. G. F. D. S. M. C. F. C. F., And Santos, R. H. A. Lanthanides-containing light-emitting organicinorganic hybrids: a bet on the future. Journal of Luminescence 128 (2008), 190-198.

[10] E. P. Barrett, L. G. J., And Halenda, P. P. The determination of pore volume and area distributions in porous substances. i. computations from nitrogen isotherms. Journal of the American Chemical Society 73 (1951), 373-380.

[11] E. Pazoz, O. Vazques, J. L. M. M. E. V. Peptide-based fluorescent biosensors. Chemical Society Reviews 38 (2009), 3348-3359.

[12] Edelmann, F. K. Lanthanides and actinides: annual survey of their organometallic chemistry covering the year 2007. Coordenation Chemical Reviews 253 (2009), 2515-2587.

[13] Eliseeva, S. V., AND BünZli, J. C. G. Lanthanide luminescence for functional materials and bio-sciences. Chemical Society Reviews 39 (2010), 189-227.

[14] G. E. Buono-Core, H. L., And Marciniak, B. Quenching of excited-states by lanthanide ions and chelates in solution. Coordination Chemistry Reviews 99 (1990), 55-87.

[15] H. F. Brito, O. L. Malta, M. C. F. C. F., and Teotonio, E. E. S. Luminescence phenomena involving metal enolates. John Wiley Sons Ltd., 2009.

[16] H. Jiang, G. Wang, W. Z. X. L. Z. Y. D. J. J. Y., And Liu, Z. Preparation and time-resolved luminescence bioassay application of multicolor luminescent lanthanide nanoparticles. Journal of Fluorescence 20 (2010), 321-328.

[17] Hui Yu, Dong-mei Jiang, Q.-Z. Z. W.-H. H., And Fan, L. Photonic and nanobiophotonic properties of luminescent lanthanide-doped hybrid orgniac-inorganic materials. Journal of Materials Chemistry 18 (2008), 23-40.

[18] Hui Yu, Dong-Mei Jiang, Q.-Z. Z. W.-H. H., And Fan, L. Preparation and luminescence of (sba-15- $\mathrm{eu}_{2} \mathrm{O}_{3}$ composite materials. Journal of Luminescence 132 (2012), 474-477.

[19] I. Hemmilä, V. L. Progress in lanthanides as luminescent probes. Journal of Fluorescence 15, 4 (2005), 529-542.

[20] L. D. Carlos, R. A. S. Ferreira, V. Z. B., And Ribeiro, S. J. L. Lanthanides-containing light-emitting organic-inorganic hybrids: a bet on the future. Advanced Materials 21 (2009), 509-534. 
[21] Li, Y., AND YAN, B. Functionalized mesoporous sba-15 with cef ${ }_{3}: \mathrm{eu}^{3}+$ nanoparticle by three different methods: Synthesis, characterization and photoluminescence. Nanoscale Res Lett 5 (2010), 701-708.

[22] Lourenço, A. V. S. Part ículas de s ílica funcionalizadas contendo complexos tr3+ para aplicação como marcadores em ensaios biol ógicos. Tese de Doutorado - Instituto de Qu ímica da Universidade de S ão Paulo (2010), 192.

[23] Luis D. Carlos, Rute A. S. Ferreira, V. D. Z. B., and Ribeiro, S. J. L. Lanthanide-containing light-emitting organic-inorganic hybrids: A bet on the future. Advanced Materials 21 (2009), 509-534.

[24] MAsel, R. I. Principles of adsorption and reaction on solid surfaces. Journal of the American Chemical Society (1996).

[25] Masel, R. I. Principles of Adsorption and Reaction on Solid Surfaces. John Wiley \& Sons Inc., 1996.

[26] O. Veiseh, J. W. G., And Zhang, M. Q. Design and fabrication of magnetic nanoparticles for target drug delivery and imaging. Advanced Drug Delivery Reviews 62 (2010), 284-304.

[27] S. Brauner, P. H. E., And Teller, E. Adsorption of gases in multimolecular layers. Journal of the American Chemical Society 60 (1938), 309-319.

[28] Sing, K. S. W., Everett, D. H., Haul, R. A. W., Moscou, L., Pierotti, R. A., Rouquérol, J., And Siemieniewska, T. Reporting physisorpion data for gas/solid systems with special reference to the determination of surface area and porosity. Pure \& Applied Chemistry 57 (1985), 603-619.

[29] Tabacniks, M. H. Análise de filmes finos por pixe e rbs. 1-17.

[30] Wei-Kan Chu, J. W. M., And Nicolet, M.-A. Backscattering Spectrometry. Harcourt Brace Jovanovich, 1978.

[31] Ya-Juan Li, Xudong Yu, X. W., And Yang, M. Lanthanide $\left(\mathrm{eu}^{3}+, \mathrm{tb}^{3}+\right)$ functionalized sba-15 through modified hexafluoroacetylacetone linkage: Covalently bonding construction, physical characterization and luminescent properties. Journal of Materials Research 29, 5 (2014).

[32] YAn, B., AND Kong, L. L. Binary and ternary heterometallic $\left(\mathrm{la}^{3}+, \mathrm{gd}^{3}+, \mathrm{y}^{3}+\right)$ $\mathrm{eu}^{3}+$ functionalized sba-15 mesoporous hybrids: Chemically bonded assembly and photoluminescence. Nanoscale Res Lett 5 (2010), 1195-1203. 
[33] YAN, J., AND WANG, G. Lanthanide-based luminescence probes and timeresolved luminescence bioassays. Trends in Analytical Chemistry 25 (2006), 490500.

[34] Ying Li, Jielin Wang, W. C. Z. J., And Li, X. Coordination assembly and characterization of europium (iii) complexes covalently bonded to sba- 15 directly functionalized by modified polymer. RSC Advances 3 (2013), 14057-14065. 


\section{Referências Bibliográficas}

[1] Barrett, E. P., Joyner, L. G., And Halenda, P. P. The determination of pore volume and area distributions in porous substances. I. computations from nitrogen isotherms. Journal of the American Chemical Society 73, 1 (January 1951), 373-380.

[2] Bing YAN, L. Z., AND Li, Y. Hydrothermal synthesis, physical characterization and photoluminescence of homologous-sba-15 fabricated with $\mathrm{eu}^{3}+$. Colloids and Surfaces A: Physicochemical and Engineering Aspects 350 (2009), 147-153.

[3] C. T. Kresge, M. E. Leonowicz, W. J. R. J. C. V., And Beck, J. S. Ordered mesoporous molecular sieves synthesized by a liquid-crystaltemplate mechanism. Nature (1992), 710-712.

[4] Chao Zhang, S. G., And Xu, H. Controllable preparation and fluorescence properties of $\mathrm{y}^{3}+$ and $\mathrm{eu}^{3}+$ co-doped mesoporous silica. Journal of Solid State Chemistry 183 (2014), 1409-1415.

[5] Ciesla, U., AND SchÜth, F. Ordered mesoporous materials. Microporous and Mesoporous Materials 27 (1999), 131-149.

[6] Craievich, A. F. Small-angle X-ray scattering by nanostructured materials Handbook of Sol-Gel Science and Technology - Volume II: Materials characterization. Chapter 8. Kluwer Academic Publishers, 2005.

[7] Crepaldi, E. L., Soler-Illia, G. J., Grosso, D., Cagnol, A. B., And SANCHEZ, C. Controlled formation of highly ordered cubic and hexagonal mesoporous nanocrystalline yttria-zirconia and ceria-zirconia thin films exhibiting high thermal stability. Angewandte Chemie 42 (2003), 347-351.

[8] Cullity, B. D., And Stock, S. R. Elements of X-ray Diffraction. Prentice Hall, 2001. 
[9] E. E. S. Teotonio, G. M. Fett, H. F. B. W. M. F. G. F. D. S. M. C. F. C. F., And Santos, R. H. A. Lanthanides-containing light-emitting organicinorganic hybrids: a bet on the future. Journal of Luminescence 128 (2008), 190-198.

[10] E. P. Barrett, L. G. J., And Halenda, P. P. The determination of pore volume and area distributions in porous substances. i. computations from nitrogen isotherms. Journal of the American Chemical Society 73 (1951), 373-380.

[11] E. Pazoz, O. Vazques, J. L. M. M. E. V. Peptide-based fluorescent biosensors. Chemical Society Reviews 38 (2009), 3348-3359.

[12] Edelmann, F. K. Lanthanides and actinides: annual survey of their organometallic chemistry covering the year 2007. Coordenation Chemical Reviews 253 (2009), 2515-2587.

[13] Eliseeva, S. V., AND Bünzli, J. C. G. Lanthanide luminescence for functional materials and bio-sciences. Chemical Society Reviews 39 (2010), 189-227.

[14] G. E. Buono-Core, H. L., And Marciniak, B. Quenching of excited-states by lanthanide ions and chelates in solution. Coordination Chemistry Reviews 99 (1990), 55-87.

[15] H. F. Brito, O. L. Malta, M. C. F. C. F., and Teotonio, E. E. S. Luminescence phenomena involving metal enolates. John Wiley Sons Ltd., 2009.

[16] H. Jiang, G. Wang, W. Z. X. L. Z. Y. D. J. J. Y., And LiU, Z. Preparation and time-resolved luminescence bioassay application of multicolor luminescent lanthanide nanoparticles. Journal of Fluorescence 20 (2010), 321-328.

[17] Hui Yu, Dong-mei Jiang, Q.-Z. Z. W.-H. H., And Fan, L. Photonic and nanobiophotonic properties of luminescent lanthanide-doped hybrid orgniac-inorganic materials. Journal of Materials Chemistry 18 (2008), 23-40.

[18] Hui Yu, Dong-Mei Jiang, Q.-Z. Z. W.-H. H., And Fan, L. Preparation and luminescence of (sba-15- $\mathrm{eu}_{2} \mathrm{O}_{3}$ composite materials. Journal of Luminescence 132 (2012), 474-477.

[19] I. Hemmilä, V. L. Progress in lanthanides as luminescent probes. Journal of Fluorescence 15, 4 (2005), 529-542.

[20] L. D. Carlos, R. A. S. Ferreira, V. Z. B., And Ribeiro, S. J. L. Lanthanides-containing light-emitting organic-inorganic hybrids: a bet on the future. Advanced Materials 21 (2009), 509-534. 
[21] Li, Y., AND YAN, B. Functionalized mesoporous sba-15 with cef ${ }_{3}: \mathrm{eu}^{3}+$ nanoparticle by three different methods: Synthesis, characterization and photoluminescence. Nanoscale Res Lett 5 (2010), 701-708.

[22] Lourenço, A. V. S. Part ículas de s ílica funcionalizadas contendo complexos tr3+ para aplicação como marcadores em ensaios biol ógicos. Tese de Doutorado - Instituto de Qu ímica da Universidade de S ão Paulo (2010), 192.

[23] Luis D. Carlos, Rute A. S. Ferreira, V. D. Z. B., and Ribeiro, S. J. L. Lanthanide-containing light-emitting organic-inorganic hybrids: A bet on the future. Advanced Materials 21 (2009), 509-534.

[24] MAsel, R. I. Principles of adsorption and reaction on solid surfaces. Journal of the American Chemical Society (1996).

[25] Masel, R. I. Principles of Adsorption and Reaction on Solid Surfaces. John Wiley \& Sons Inc., 1996.

[26] O. Veiseh, J. W. G., And Zhang, M. Q. Design and fabrication of magnetic nanoparticles for target drug delivery and imaging. Advanced Drug Delivery Reviews 62 (2010), 284-304.

[27] S. Brauner, P. H. E., And Teller, E. Adsorption of gases in multimolecular layers. Journal of the American Chemical Society 60 (1938), 309-319.

[28] Sing, K. S. W., Everett, D. H., Haul, R. A. W., Moscou, L., Pierotti, R. A., Rouquérol, J., And Siemieniewska, T. Reporting physisorpion data for gas/solid systems with special reference to the determination of surface area and porosity. Pure \& Applied Chemistry 57 (1985), 603-619.

[29] Tabacniks, M. H. Análise de filmes finos por pixe e rbs. 1-17.

[30] Wei-Kan Chu, J. W. M., And Nicolet, M.-A. Backscattering Spectrometry. Harcourt Brace Jovanovich, 1978.

[31] Ya-Juan Li, Xudong Yu, X. W., And Yang, M. Lanthanide $\left(\mathrm{eu}^{3}+, \mathrm{tb}^{3}+\right)$ functionalized sba-15 through modified hexafluoroacetylacetone linkage: Covalently bonding construction, physical characterization and luminescent properties. Journal of Materials Research 29, 5 (2014).

[32] YAn, B., AND Kong, L. L. Binary and ternary heterometallic $\left(\mathrm{la}^{3}+, \mathrm{gd}^{3}+, \mathrm{y}^{3}+\right)$ $\mathrm{eu}^{3}+$ functionalized sba-15 mesoporous hybrids: Chemically bonded assembly and photoluminescence. Nanoscale Res Lett 5 (2010), 1195-1203. 
[33] YAN, J., AND WANG, G. Lanthanide-based luminescence probes and timeresolved luminescence bioassays. Trends in Analytical Chemistry 25 (2006), 490500.

[34] Ying Li, Jielin Wang, W. C. Z. J., And Li, X. Coordination assembly and characterization of europium (iii) complexes covalently bonded to sba- 15 directly functionalized by modified polymer. RSC Advances 3 (2013), 14057-14065. 